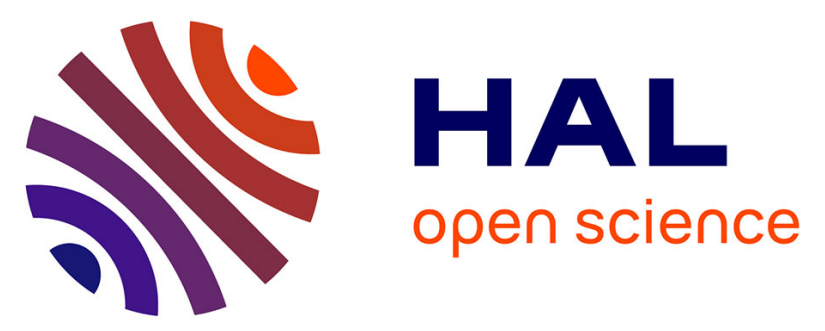

\title{
Development of Novel Versatile Theranostic Platforms Based on Titanate Nanotubes: Towards Safe Nanocarriers for Biomedical Applications
}

\author{
Julien Boudon, Fadoua Sallem, Alexis Loiseau, Lionel Maurizi, Anne-Laure
} Papa, Nadine Millot

\section{To cite this version:}

Julien Boudon, Fadoua Sallem, Alexis Loiseau, Lionel Maurizi, Anne-Laure Papa, et al.. Development of Novel Versatile Theranostic Platforms Based on Titanate Nanotubes: Towards Safe Nanocarriers for Biomedical Applications. New Trends in Macromolecular and Supramolecular Chemistry for Biological Applications, Springer International Publishing, pp.151-178, 2021, 10.1007/978-3-030-57456-7_8 . hal-03276177

\section{HAL Id: hal-03276177 \\ https://hal.science/hal-03276177}

Submitted on 1 Jul 2021

HAL is a multi-disciplinary open access archive for the deposit and dissemination of scientific research documents, whether they are published or not. The documents may come from teaching and research institutions in France or abroad, or from public or private research centers.
L'archive ouverte pluridisciplinaire HAL, est destinée au dépôt et à la diffusion de documents scientifiques de niveau recherche, publiés ou non, émanant des établissements d'enseignement et de recherche français ou étrangers, des laboratoires publics ou privés. 


\title{
Development of novel versatile theranostic platforms based on titanate nanotubes: towards safe nanocarriers for biomedical applications
}

\author{
Julien BOUDON ${ }^{1}$, Fadoua SALLEM ${ }^{1}$, Alexis LOISEAU ${ }^{1}$, Lionel MAURIZI ${ }^{1}$, Anne-Laure PAPA ${ }^{2}$, \\ Nadine MILLOT ${ }^{1}$ \\ ${ }^{1}$ Laboratoire ICB, UMR 6303 CNRS/Université Bourgogne Franche-Comté, 9 Avenue Alain Savary, \\ 21078 Dijon, France. \\ ${ }^{2}$ Department of Biomedical Engineering, The George Washington University, Washington, DC 20052, \\ USA.
}

\section{Abstract}

The concept of nanomaterials that can be designed and administered into the human body to improve health is of great interest. During the past years there has been an increasing amount of research on the uses of nanomaterials in diverse areas of biomedical research including biological sensing, labelling, imaging, cell separation and therapy. In this chapter, the first evaluation of titanate nanotubes (TiONts) as potential carriers of therapeutic molecules is presented. TiONts with controlled parameters have been developed from a hydrothermal synthesis and their biomedical applications have been explored over the last decade. These nanotubes are elaborated as stable suspensions of nanocarriers by surface chemistry engineering. They can be used as transfection agents for cardiomyocytes and we have shown that TiONts can increase the ionizing effect of radiation therapy in the case of glioblastoma. Furthermore, TiONts' biodistribution has been evaluated by SPECT/CT in male Swiss nude mice and TiONts are quickly cleared. More recently, we have demonstrated that TiONts-docetaxel (DTX) nanohybrids are versatile nanocarriers to limit the systemic toxicity of taxanes and to improve the selectivity of radiotherapy (RT). Our strategy is based on the intraprostatic injection of the TiONts-DTX nanohybrids both in place of brachytherapy and in combination with RT. This is achieved by taking advantage of the TiONts' morphology as well as their radiosensitization effect and by associating them with docetaxel molecules, also recognized for their radiosensitizing potential. We also grafted the surface of TiONts with gold nanoparticles, for a resulting combined radiosensitizing effect. The elaboration of nanohybrid materials, intended for drug delivery systems and based on TiONts coated with chitosan polymer has also been evaluated. Such nanotubes are combined with transresveratrol derivatives for their anti-oxidizing and antitumor effects. All the aspects of a potential toxicity are also considered.

Keywords: Titanate nanotubes, theranostic platform, nanomedicine, nanocarriers, chemistry, nanohybrids, characterizations 


\section{Introduction}

The shape of nanoparticles is an essential element to take into account for the internalization, cytotoxicity, biodistribution and intracellular exchanges of nano-objects in the organism (Ernsting et al. 2013).

Diffusion phenomena, through the cells' membrane, have already been observed by anisotropic nanoparticles, allowing the internalization of these biomaterials in the cytoplasm in addition to endocytosis (Kostarelos et al. 2007). Besides, it was demonstrated that anisotropic nanoparticles were characterized by a higher blood circulation time and prolonged retention at tumor sites compared to spherical nanoparticles (Agarwal et al. 2015). Z.J. Deng et al. have shown that the shape of $\mathrm{TiO}_{2}$ nanoparticles (nanosphere, nanorod and nanotube) plays an important role in the absorption of proteins on their surface, thus dictating their biokinetics and their behavior in vivo (Deng et al. 2009). Intrinsic properties of nanoparticles are also influenced by their shape. It has been shown that magnetic nanoparticles of elongated shape exhibit higher magnetic hyperthermia heating capacities than their spherical equivalents (Das et al. 2016). Similarly, gold nanorods have interesting optical properties due to the resonance effects of the surface plasmon. Finally, excellent properties associated with guided geometry nanoparticles have opened up exciting opportunities for new material designs and will potentially revolutionize the current practice in Biology and Medicine (Decuzzi et al. 2017). Nanoparticles can be built from different materials and can host a wide range of active components for various biomedical applications, including chemotherapeutics, proteins, contrast agents, and nucleic acids.

The major elongated nanoparticles used in nanomedicine are: carbon nanotubes (Bianco et al. 2005), gold nanorods (Awan et al. 2018), ZnO nanorods (Jeong et al. 2020), silver nanorods (Suganya and Devasena 2015), silica nanotubes (Ma et al. 2009), iron oxide nanorods (Singh et al. 2020), apatite nanorods (Ge et al. 2019), alumina nanotubes (Campos et al. 2016), titanium oxide nanorods (Sun et al. 2016) and titanate nanotubes (Bavykin and Walsh 2009). Gold nanorods, for instance, have been developed for biomedical applications focus on detection, biocatalysis, imaging, drug delivery, and gene delivery (Wang et al. 2013). ZnO nanorods, as for them, are suitable in biosensing and biodetection (Hahm 2016).

Titanate nanotubes (TiONts) have been used in hip prostheses and dental implants (Bavykin and Walsh 2009) and for dopamine detection (Niu et al. 2008). Our group is a pioneer in the development of TiONt-based nanovectors (Mirjolet et al. 2013; Papa et al. 2013). This chapter aims to summarize the chemical challenges and biomedical opportunities around these fascinating titanate nanotubes.

\section{The preparation of titanate nanotubes and their characterization}

\subsection{Hydrothermal synthesis of titanate nanotubes}

TiONts have historically been synthesized by two methods: (i) via hydrothermal synthesis starting from nanometric and spherical $\mathrm{TiO}_{2}$ precursor (Kasuga et al. 1998; Papa et al. 2009), which will be described in this chapter, and (ii) via electrochemical anodization of a Ti metal foil substrate (Gong et al. 2001). The parameters of these reactions (such as temperature, time, $\mathrm{pH}$, agitation, washings, etc) enable a precise control of the physico-chemical characteristics of the resulting TiONts such as shapes (Bellat $e t$ al. 2015) (tubes, sheets, ribbons), dimensions (inner/outer diameters; length), size distribution, specific surface and chemical composition. These parameters can be specifically tuned and optimized to best fit the targeted bioapplications.

The hydrothermal synthesis of TiONts is a single step process starting from $\mathrm{TiO}_{2}$ spherical nanoparticles (i.e. rutile, anatase or P25) under highly basic conditions such as $10 \mathrm{M} \mathrm{NaOH}$ (Fig. 1). The hydrothermal treatment (3-4 bar) is maintained over 12 to 72 hours and 100 to $180^{\circ} \mathrm{C}$. The formation mechanism of titanate nanotubes is still a matter of debate. Several phenomena are discussed in literature: the 
dissolution of the precursor crystallites in bulk followed by the formation of nanosheets which then curl into nanotubes (Sun and Li 2003; Bavykin et al. 2006). After this, the reaction mixture is washed by centrifugation cycles, dialyzed or ultrafiltered until the suspension reaches neutral pH. Finally, the TiONts' suspension is freeze-dried for at least 12 hours and the resulting lyophilized particles are stable for months at room temperature.

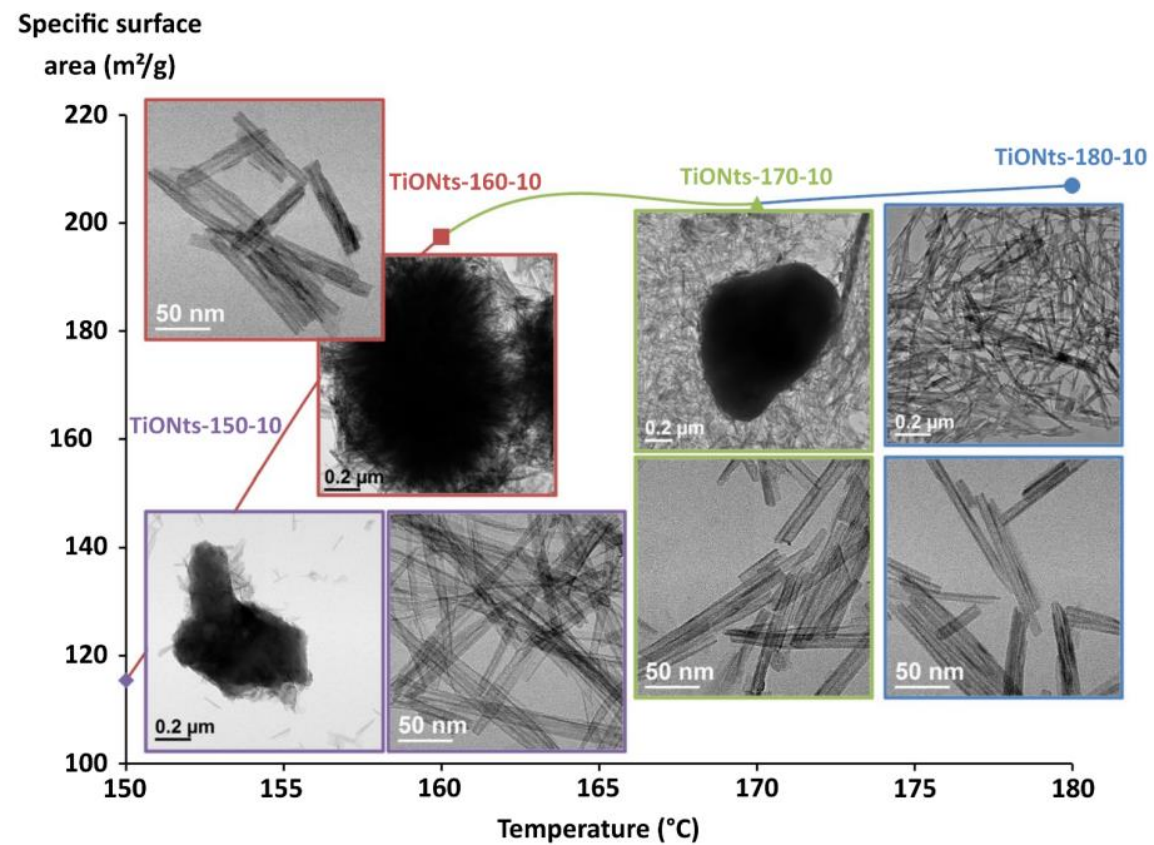

Fig. 1 - TEM images and BET specific surface of TiONts as a function of the reaction temperature (from 150 to $180^{\circ} \mathrm{C}$ ) at a fixed stirring running for $10 \mathrm{~min} / \mathrm{h}$ and for $8 \mathrm{~h}$

\subsection{Titanate nanotubes' features and characterizations}

Titanate nanotubes display a large specific surface area (higher than $200 \mathrm{~m}^{2} / \mathrm{g}$ ) due to their hollow and multilayered assembly (Sallem et al. 2017b) (Fig. 2a). Unlike carbon nanotubes, their multilayered morphology is not concentric, rather it is arranged in a spiral fashion. A large number of surface hydroxyls have been estimated by TGA (thermogravimetric analysis) and verified by XPS (X-ray photoemission spectroscopy) surface analyses. The zeta potential $(\xi)$ measurements made on TiONts indicate a maximum zeta potential value around $20 \mathrm{mV}$ and an isoelectric point (IEP) around pH 3 (Fig. $2 \mathrm{~b})$. The TiONts' surface charge varies with the $\mathrm{pH}$ according to the following equilibria:

$$
\begin{aligned}
\text { TiONts-OH } & { }^{+} \leftrightarrows \text { TiONts-OH }+\mathrm{H}^{+} \\
\text {TiONts-OH } & \leftrightarrows \text { TiONts-O }+\mathrm{H}^{+}
\end{aligned}
$$




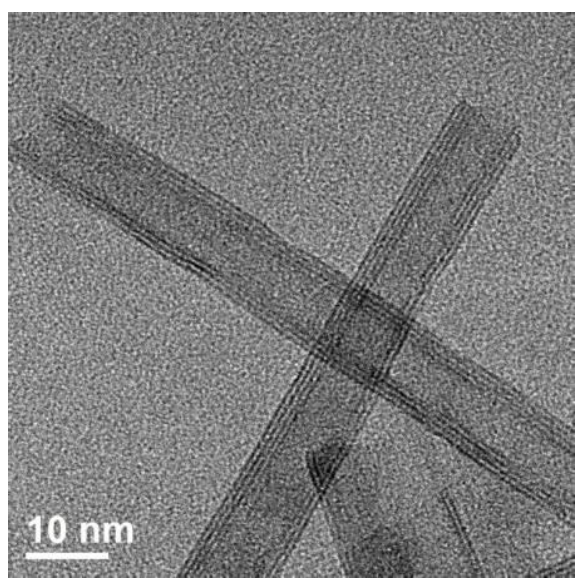

(a)

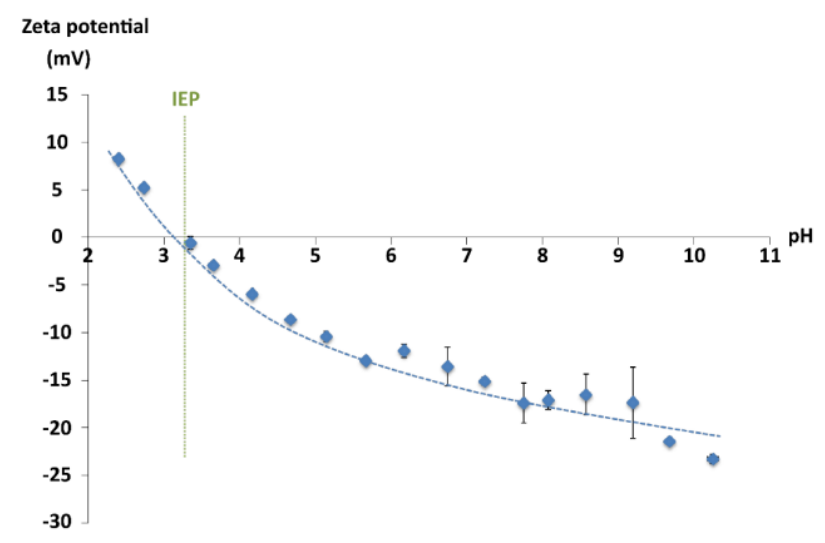

(b)

Fig. 2 - (a) TEM image of two titanate nanotubes synthesized by static hydrothermal route (no stirring, $\mathrm{T}=150^{\circ} \mathrm{C}, \mathrm{t}=$ $48 \mathrm{~h},[\mathrm{NaOH}]=10 \mathrm{M})$, (b) Zeta potential measurements of TiONts as a function of $\mathrm{pH}$ in $\mathrm{NaCl}\left(10^{-2} \mathrm{M}\right)$ 


\section{The surface modification of titanate nanotubes (synthesis and characterizations)}

Bare TiONts are not stable enough in physiological conditions ( $c a .50 \%$ of TiONts settled after 20 min and about $80 \%$ after one hour, Fig. 3ab) and require surface modifications to improve their colloidal stability: to do so alkoxysilanes, phosphonates and catechols can be interestingly used to obtain surface-modified TiONts (Fig. 3c), the description of which will be described in the following paragraphs.

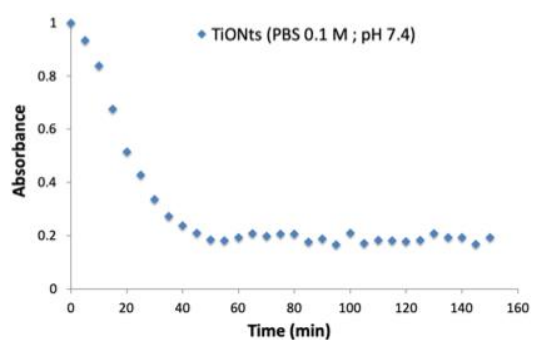

(a)

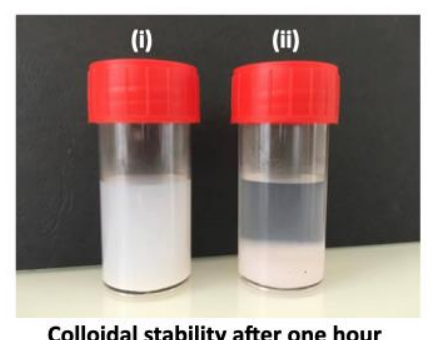

(b)

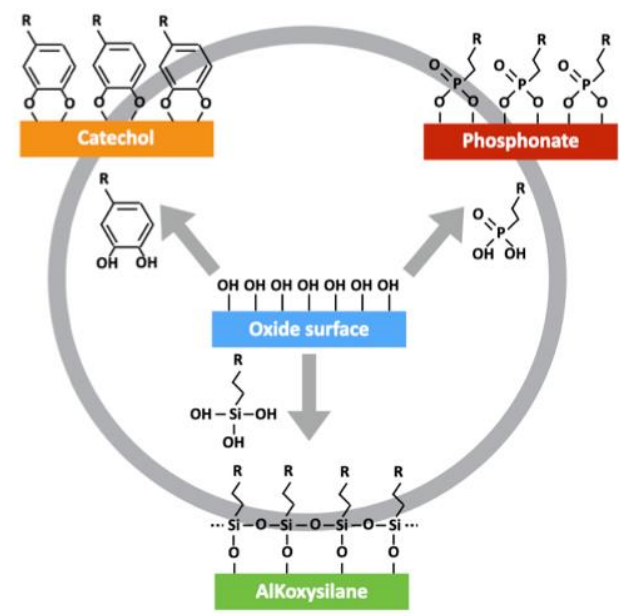

(c)

Fig. 3 - (a) Colloidal stability of bare TiONts (PBS $0.1 \mathrm{M}$; pH 7.4) over $150 \mathrm{~min}$ following their absorbance at $600 \mathrm{~nm}$ by turbidimetry. (b) Picture of bare TiONts' suspensions in (i) ultrapure water and (ii) PBS (0.1 M; pH 7.4) after one hour. (c) Illustration of different pre-functionalization strategies on the TiONts' surface by catechol, phosphonate and alkoxysilane derivatives (only one way of grafting is arbitrarily represented)

\subsection{TiONts' modification by silane derivatives}

TiONts can easily be modified by silane derivatives to yield silica-coated TiONts with a view to i) stabilize TiONts for further applications and ii) possibly bring new chemical functions provided that the silane used is terminated with an amine or a carboxylic acid group for example.

The mostly used alkoxysilane is 3-aminopropyltriethoxysilane (APTES) for which the silane function reacts with the surface hydroxyls of the TiONts and the amine function makes it possible in particular to have an electrostatic-type repulsion at the surface of the TiONts. APTES formula is $\left(\mathrm{CH}_{3} \mathrm{CH}_{2} \mathrm{O}\right)_{3}$-Si$(\mathrm{CH})_{3}-\mathrm{NH}_{2}\left(\mathrm{M}=221 \mathrm{~g} \cdot \mathrm{mol}^{-1}\right)$ (Fig. 4). It is commonly used to obtain biocompatible surfaces. This molecule is mainly used to promote protein adhesion and cell growth on biological implants (Balasundaram et al. 2006) as well as for biosensing or DNA extraction (Howarter and Youngblood 2006).

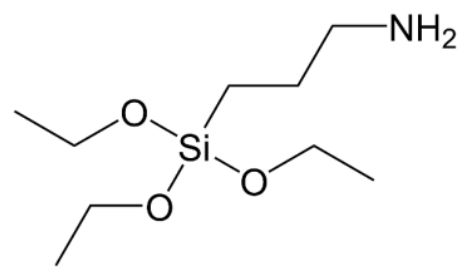

Fig. 4 - Chemical structure of the 3-aminopropyltriethoxysilane molecule 
Several steps are necessary when grafting APTES on TiONts and any consideration in the following lines could be theoretically applied to any silane derivative: other hydrolyzable groups (3aminopropyltrimethoxysilane or 3-aminopropyltrichlorosilane); other end groups (3-Rpropylalkoxysilane with $\mathrm{R}=$ epoxide, $\mathrm{Cl}-, \mathrm{N}_{3}-$, etc.); and various lengths of alkyl chains bearing the chemical function of interest ( $\omega$-R-alkylalkoxysilane). First, a reaction of APTES in aqueous solution forms a silanol with the hydrolysis of three ethanol molecules (Fig. 5a). Then, oligomerization of silanols (intermolecular condensation) leads to the formation of oligosiloxanols with different chain sizes (Fig. 5b). Then, hydrogen bonds appear between oligosiloxanols and the hydroxyls of the TiONts' surface (Fig. 5c). Finally, the last step is the condensation of oligosiloxanols on TiONts with the formation of covalent bonds (Fig. $5 \mathrm{~d}$ ).

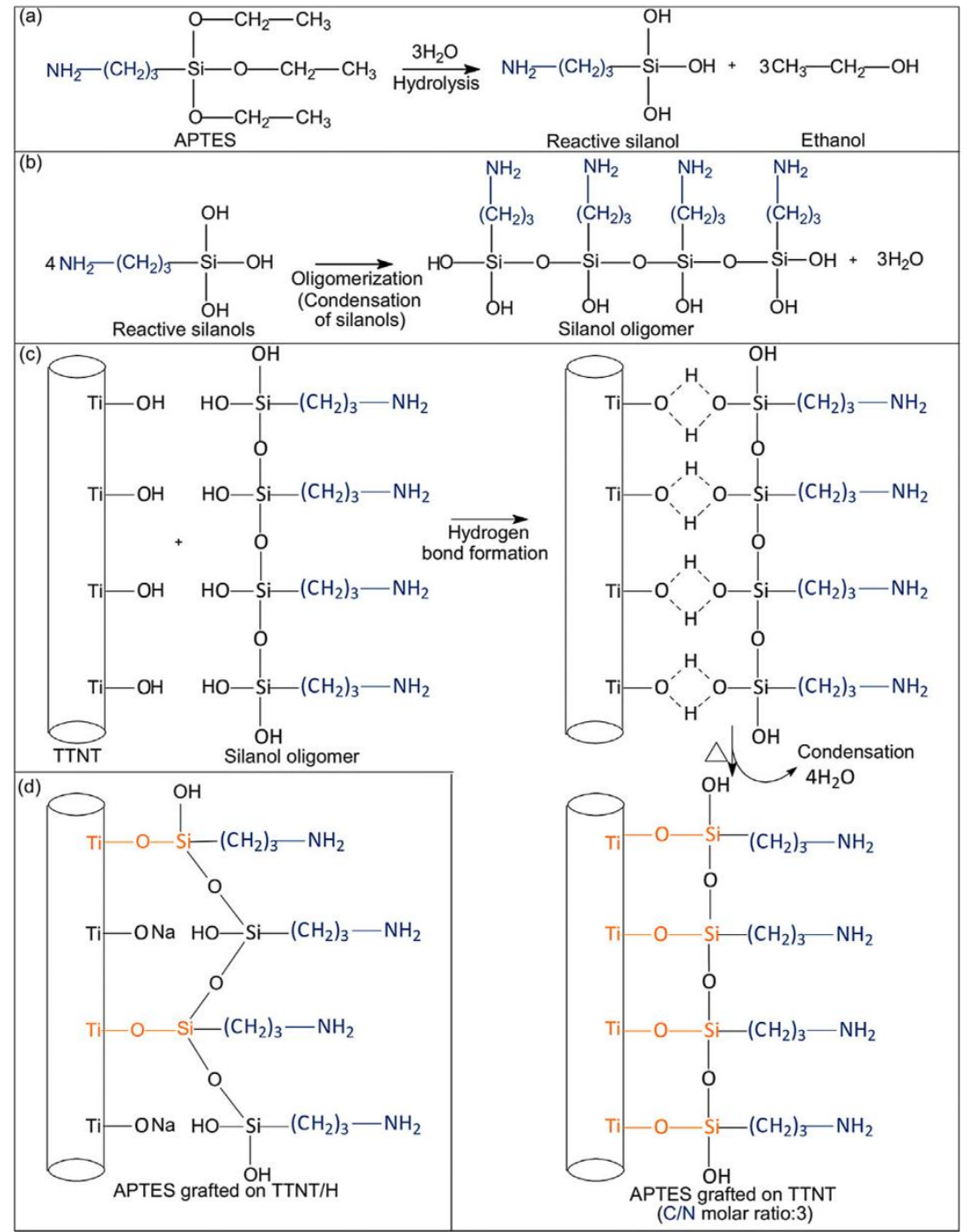

Fig. 5 - Functionalization of TiONts by APTES: (a) hydrolysis of APTES; (b) oligomerization of silanols; (c) creation of hydrogen bridges then formation of covalent bonds by condensation between the oligosiloxanols and the surface of TiONts; (d) possible incomplete condensation of silanols on the surface of TiONts. According to (Pontón et al. 2014)

It is important to control the different stages of silanization to obtain a monolayer of APTES and to be able to optimize the number of amine functions on the surface of TiONts for subsequent grafting. Indeed, it is possible to create multilayers of APTES during condensation (Fig. 6) and to affect the final structure of the layer of aminosilane on the surface of the inorganic substrate. This is notably due to several parameters such as water content, reaction temperature, concentration, and nature of the silane (White and Tripp 2000). Among these, temperature, and proportion of solvent (ratio water/ethanol) are the main parameters which play on the structure and on the grafting rate of APTES. 
In fact, an increase in temperature favors the condensation of the polysiloxane on the TiONts' surface as well as the reaction speed, while the proportion of the solvent can affect the competitive reactions between hydrolysis and oligomerization (Liu et al. 2013).

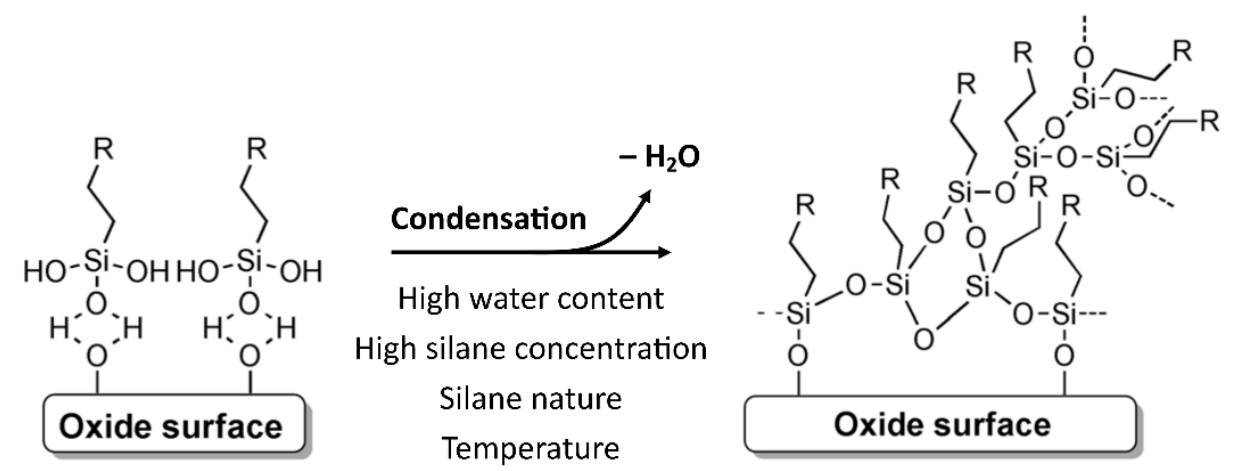

Fig. 6 - Scheme of APTES multilayers on the inorganic substrate during condensation. According to (Pujari et al. 2014)

Recently, N. Millot et al. have developed advanced surface-modified TiONts for biomedical applications including a first coating of silane derivatives (APTES in the following examples) prior to further functionalization(s): polymer-coated TiONts (Papa et al. 2015), TiONts as optical probe thanks to phthalocyanines (Boudon et al. 2014; Paris et al. 2015), docetaxel nanocarriers (Mirjolet et al. 2017; Loiseau et al. 2017), chitosan-coated TiONts (Sallem et al. 2017a), or also TiONts as potential candidate for drug delivery applications across the brain (Sruthi et al. 2018).

\subsection{TiONts' modification by phosphonate derivatives}

Phosphonic acids and their derivatives $\left(\mathrm{R}-\mathrm{PO}(\mathrm{OR})_{2} ; \mathrm{R}, \mathrm{R}^{\prime}=\right.$ hydrogen, alkyl) have become increasingly attractive due to their strong affinity for hydroxylated surfaces (Ries and Cook 1954). They have already proven themselves in biological fields for biosensors or for medical implants (Mutin et al. 2005). The chemisorption mechanisms of phosphonate agents on inorganic substrates are greatly affected by reaction conditions such as temperature, $\mathrm{pH}$ of the medium, concentration, solvent and type of oxide (Pujari et al. 2014). The type of interaction between the phosphorus atom and the hydroxyl oxygen can differ depending on the Lewis strength of the atoms on the surface of the metal oxide (Fig. 7a). Indeed, in the case of a surface with high Lewis acidity, the bonds (P-O-M) are even more stable and stronger as the $\mathrm{P}$ atom becomes more electrophilic and induces consecutive heterocondensations with hydroxyls. Otherwise, hydrogen bonds can form due to a higher affinity with phosphonate and hydroxyls on the surface of the metal oxide. In addition, the presence of three oxygen atoms on the phosphonates makes it possible to induce three modes of chelation (mono-, bi- and tridentate). The oxygen can then be linked to the same metal site or to different atoms present on the surface (Fig. $7 \mathrm{~b}$ ) (Guerrero et al. 2013).

The phosphonates are then interesting, in comparison with the alkoxysilanes, because they form stable monolayers. In addition, they are less likely to become detached from the surface of the oxide by selfcondensation reactions which can break the bonds formed. However, this can happen under high temperature dehydration conditions (Mutin et al. 2005). Also, the handling conditions (phosphonate coupling reactions are often optimized in water) and storage (in air at $20^{\circ} \mathrm{C}$ ) make them more accessible and less restrictive than aminosilanes or catechols. In addition, phosphonic acids have remarkable affinities with metal oxides having a high degree of oxidation such as titanium $\left(\mathrm{Ti}^{4+}\right)$ (Guerrero et al. 2001). The hydrolytic stabilities of monolayers during the formation of P-O-M bonds are then better than in the case of alkoxysilanes and are comparable to those of catechols (Daou et al. 2007; Pujari et al. 2014). 
(a)

(i)

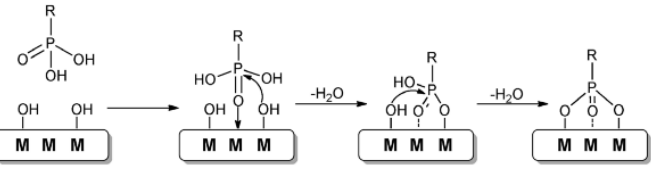

(ii)
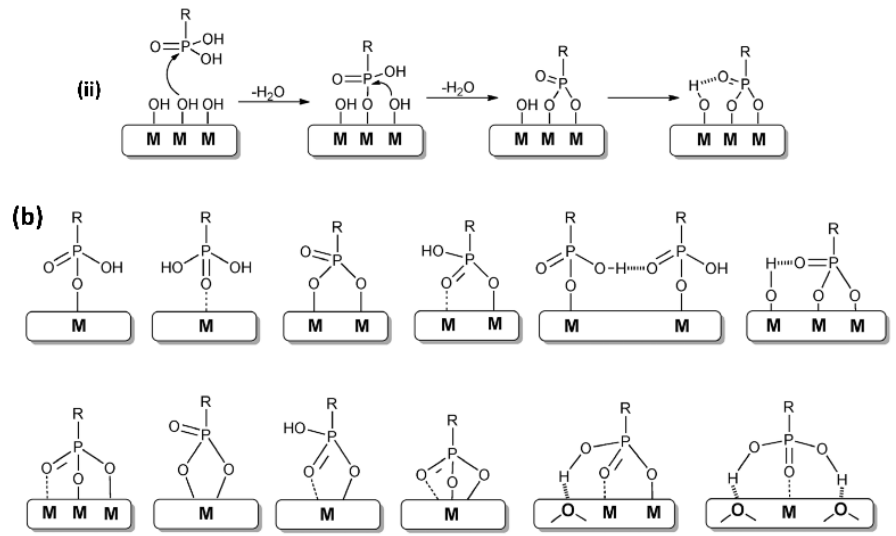

Fig. 7 - (a) Presentation of the two main mechanisms for grafting a phosphonate type agent onto a metal oxide surface. (b) Illustration of the different conformations between a phosphonate and the surface of a metal oxide (mono-, bi- and tridentate chelation). According to (Pujari et al. 2014)

Finally, phosphonates can also be bifunctional molecules. On the one hand, the phosphonate group should have a strong affinity with the surface of TiONts and on the other hand, a reactive function is present to generate an electrostatic effect capable of improving the colloidal stability of the nanotubes and to then graft other molecules. An example of phosphonates is the monophosphonate 6phosphonohexanoic acid (PHA, Fig. 8): the phosphonic side interacts with the metal oxide surface and the opposite side of the molecule is ended by a carboxylic acid function for further functionalization.

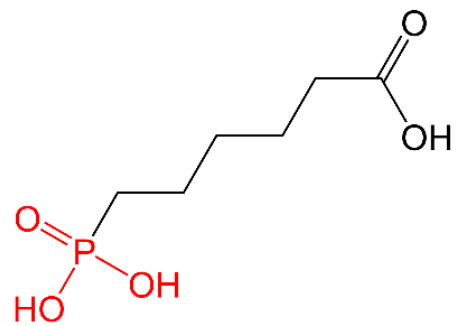

Fig. 8 - Chemical structure of the monophosphonate 6-phosphonohexanoic acid molecule

N. Millot et al. have investigated three different types of phosphonate grafting to improve the colloidal stability of TiONts: the 6-phosphonohexanoic acid monophosphonate (PHA, Fig. 8), the alendronic acid bisphosphonate (ALD, Fig. 9a) or a PEGylated monophosphonate (Fig. 9b). These agents are all heterobifunctional molecules and the PHA has already been studied in our laboratory on iron oxide nanoparticles but also during initial investigations on TiONts (Paris et al. 2015; Thomas et al. 2016). PHA has a carboxylic function at one end, while the alendronate and the PEG (polyethylene glycol) derivative have an amine function in addition to the phosphonate function. 
<smiles>NCCCC(O)(P(=O)(O)O)P(=O)(O)O</smiles>

(a)<smiles>CC(C)(N)CCOC(C)(C)N</smiles>

(b)

Fig. 9 - Chemical structure of (a) the bisphosphonate alendronic acid molecule and (b) the $\omega$-amino-PEG-monophosphonate

The influence of a monophosphonate and a bisphosphonate on colloidal stability under physiological conditions have been compared. The alendronic acid is particularly interesting because it is already used as an anticancer drug (anti-tumor properties), for the treatment of osteoporosis and for other bone diseases (Benyettou et al. 2011; Motte et al. 2011). Finally, the presence of a long carbon chain, with a phosphonate group on one end and an amine function on the other, allows a steric effect and an electrostatic effect to occur thus improving the colloidal stability with the phosphonate-type polymer.

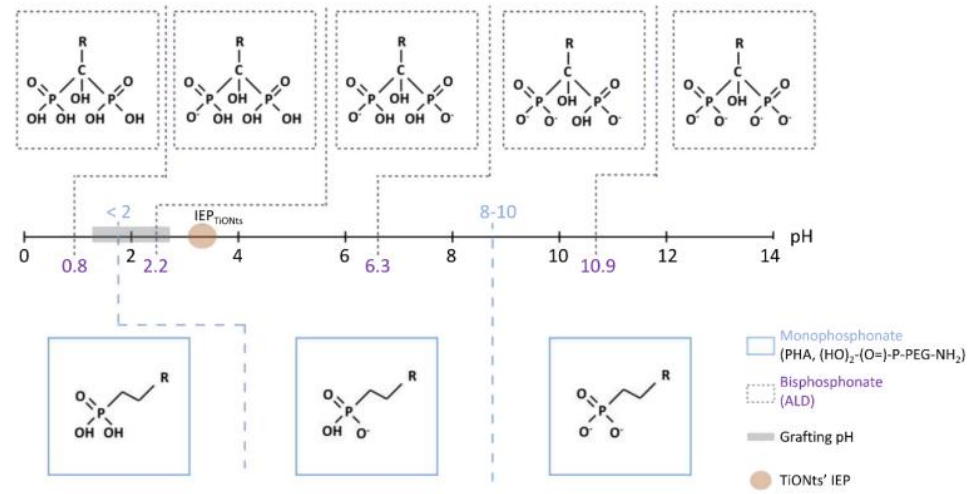

Fig. 10 - Different acid-base forms of monophosphonates (PHA and

$\left.(\mathrm{HO})_{2}-(\mathrm{O}=) \mathrm{P}-\mathrm{PEG}-\mathrm{NH}_{2}\right)$ and bisphosphonate $(\mathrm{ALD})$ depending on the $\mathrm{pH}$ range

As depicted in Fig. 10, it should be noted that alendronic acid has five pKa $\left(\mathrm{pKa}_{1}=0.8 / \mathrm{pKa}_{2}=2.2\right.$ / $\mathrm{pKa}_{3}=6.3 / \mathrm{pKa}_{4}=10.9$ as regards the pairs of the two phosphonates $\mathrm{POOH} / \mathrm{POO}^{-}$and $\mathrm{pKa}_{5}=12.2$ for the $\mathrm{NH}_{3}{ }^{+} / \mathrm{NH}_{2}$ pair, Fig. 9a). In a previous study, alendronate was grafted to the surface of maghemite nanoparticles at pH 2 via two Fe-O-P bonds (corresponding to $\mathrm{pKa}_{1}$ and $\mathrm{pKa}_{2}$ ) (Benyettou et al. 2011). In the same study, it is shown that at pH 7.4, the negative charge of the obtained nanohybrid is due to the deprotonation of the $\mathrm{OH}$ function of the couple relative to pkas. In theory, to promote the grafting of the alendronate via two Fe-O-P bonds, it is preferable to have $\mathrm{pH}$ between 2.2 and 6.3. However, the TiONts' IEP is ca. 3 (Fig. 2b) (Papa et al. 2015). Thus, to form Ti-O-P bonds, it is preferable have pH below 3 (Fig. 10). Note that at pH 7.4, the agglomeration of TiONts is weaker than at acidic pH (the $\zeta-$ potential is $-35 \mathrm{mV}$ due to deprotonated hydroxyl groups). It is the same with $\mathrm{PHA}$ and $(\mathrm{HO})_{2}-(\mathrm{O}=) \mathrm{P}-$ PEG-NH $\mathrm{NH}_{2}$ for which the pKa of phosphonate are between 2 and 8.5. Finally, the choice of pH must consider the pKa of these three molecules, their solubility but also, the IEP and the colloidal stability of the TiONts.

The dispersion state of TiONts, after the different graftings of PHA, ALD and of polymer $(\mathrm{HO})_{2}-(\mathrm{O}=) \mathrm{P}-$ PEG-NH ${ }_{2}$ has been analyzed by TEM (Fig. 11). In these pictures, the grafts for the TiONts-ALD and the TiONts-PHA seem to favor the individualization of the nanohybrids, unlike naked nanotubes which are organized in bundles (Papa et al. 2009; Boudon et al. 2014) even if they sometimes form a few small agglomerates. This attests that the surface modification of TiONts by ALD and PHA greatly improves 
their dispersion. However, it is the TiONts-PEG-NH $\mathrm{NH}_{2}$ wich show better dispersion on the observation grid while they have been found to be less stable by UV-visible spectroscopy. They exhibit a homogeneous dispersion over the entire surface, without agglomerate: it is therefore the polymer chains which contribute sterically to this individualization. This remarkable state of dispersion (better than with the TiONts / APTES / PEG system) allows synthetic by-products to be visualized, such as nanoribbons, but in negligible amount compared to the number of nanotubes.

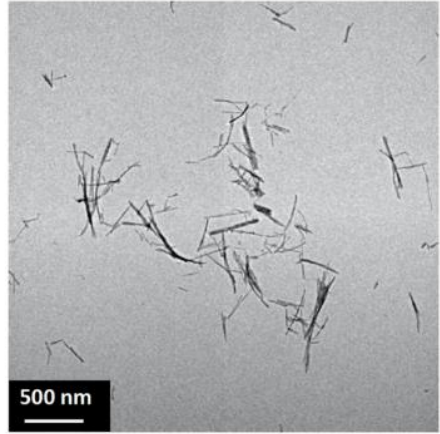

(a)

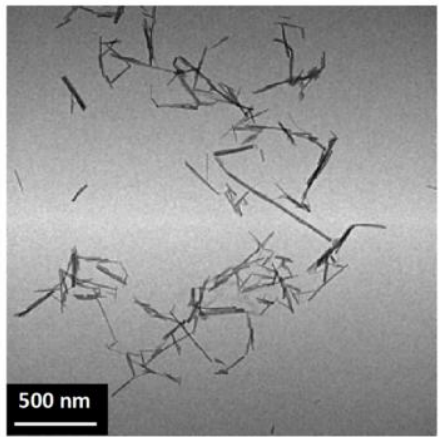

(b)

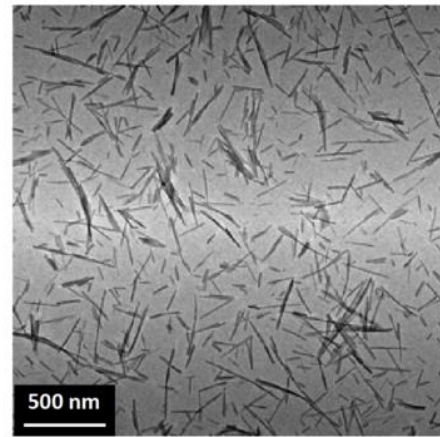

(c)

Fig. 11 - TEM images showing the dispersion state of different functionalized-TiONts by phosphonate derivatives: (a) TiONts-PHA, (b) TiONts-alendronate and (c) TiONts-PEG-NH

\subsection{TiONts' modification by catechols}

The applications of nanopowders in suspension are often limited by the insufficient colloidal stability of nanoparticles. Catechols have good properties as stabilizers (Amstad et al. 2009, 2011a) to remedy this; they also exhibit antioxidant activity (Lee et al. 2003). Catechols generally form a charged monolayer on the surface of metal oxide, which stabilizes nanoparticles to absorb light or to lead to reversible redox reactions and they present as well an interesting potential barrier for photovoltaic and biomedical applications (Pujari et al. 2014). Catechol derivatives are used as dispersants for various oxides, in particular with titanium and iron oxides (Amstad et al. 2011a; Bahri et al. 2011). Despite similar chemical properties between different catechols, the affinities on these oxides vary considerably. Catechols can form weakly reversible or strong bonds, depending on their affinity with the cations of the oxides (Amstad et al. 2011b). The grafting mechanism of catechols on oxides is relatively close to that of phosphonates (paragraph 2.2). Briefly, a mono- or bidentate complex can form with one or two oxygen from the catechols and the metal atoms from the oxide, as is the case with titanium.

Moreover, $\mathrm{pH}$ is a key parameter in the grafting and conformation of catechols on the surface of metal oxide. In addition to being the main oxidation factor for catechols, the protonation state of the different groups depends on $\mathrm{pH}$ (Fig. 12a). Thus, concentration and $\mathrm{pH}$ of the reaction medium influence the grafting capacity of catechols (pKa of the catechols' hydroxyls have a value of between 8.5 and 10), as well as the conformation of the molecule on the surface of the oxide (Fig. 12b). 

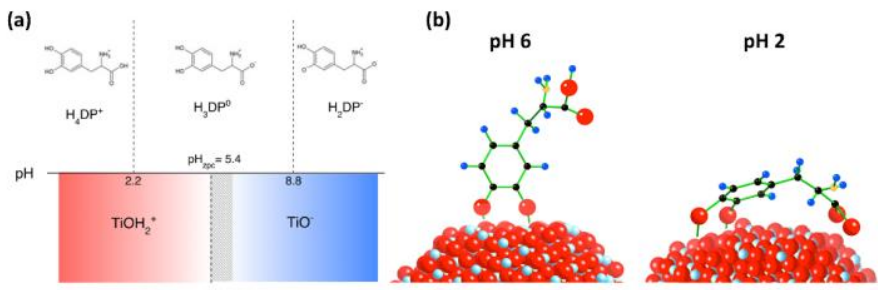

Fig. 12 - Illustration of the state (a) of protonation and (b) conformation of catechols (LDOPA) dependent on $\mathrm{pH}$, on a surface of titanium dioxide (Lee et al. 2012)

A study related to the grafting of L-3,4-dihydroxyphenylalanine (LDOPA) on $\mathrm{TiO}_{2}$, has shown that $\mathrm{pH} 6$ favors a stretched conformation and an orientation perpendicular to the surface of nanoparticles (which has also been observed with a high concentration of catechol during grafting) unlike $\mathrm{pH} 2$ for which the molecule seems to be lying on the surface of $\mathrm{TiO}_{2}$ (Fig. 12b) (Lee et al. 2012). It is therefore preferable to have a $\mathrm{pH}$ around 6 on a $\mathrm{TiO}_{2}$ surface to optimize the grafting of catechols and lead to available reactive functions. Furthermore, excessive basic $\mathrm{pH}$ promotes the oxidation of catechols (Bahri et al. 2011): the choice of $\mathrm{pH}$ is therefore essential to obtain an optimal conformation of the molecule while limiting its oxidation for future grafting. The grafting of three hydrophilic catechols has been carried out to modify the surface of TiONts: L-3,4-dihydroxyphenylalanine (LDOPA), 3,4dihydroxyhydrocinnamic acid (DHCA) and nitrodopamine (NDOPA) (Fig. 13). These molecules have one or many reactive functions in addition to the catechol group so that colloidal stability is improved by electrostatic repulsion $\left(-\mathrm{COOH},-\mathrm{NH}_{2},-\mathrm{NO}_{2}\right)$. These same functions allow subsequent grafting of molecules such as polymers, therapeutic or chelating agents. In addition, the hydroxyls of catechols have a very strong affinity with titanium oxides (Amstad et al. 2009).<smiles>N[C@@H](Cc1ccc(O)c(O)c1)C(=O)O</smiles>

(a)<smiles>O=C(O)CCc1ccc(O)c(O)c1</smiles>

(b)<smiles>NCCc1cc(O)c(O)cc1[N+](=O)[O-]</smiles>

(c)

Fig. 13 - (a) L-3,4-dihydroxyphenylalanine (LDOPA), (b) 3,4-dihydroxyhydrocinnamic acid (DHCA) and (c) nitrodopamine (NDOPA) molecules

The grafting of DHCA and LDOPA catechols can be carried out under pH 6 because it leads to a fairly good dispersion of TiONts in water (value far from the IEP of bare TiONts), a pH close to the pKa of both catechol hydroxyls (to promote grafting) and allows the oxidation of catechols to be limited as it occurs at strongly acidic or basic $\mathrm{pH}$ (LDOPA: $\mathrm{pKa}_{\mathrm{COOH}}=2.3, \mathrm{pKa}_{\mathrm{NH} 2}=9.7, \mathrm{pKa}_{\mathrm{OH}}=8.7$ and 13.4; DHCA: $\mathrm{pKa}_{\mathrm{COOH}}=4.2, \mathrm{pKa}_{\mathrm{OH}}=9.2$ and 11.7; NDOPA: $\mathrm{pKa}_{\mathrm{NH} 2}=8.7, \mathrm{pKa}_{\mathrm{NO} 2}=6.7, \mathrm{pKa}_{\mathrm{OH}}=6.5$ and 10.3) (Amstad et al. 2011a; Togashi et al. 2012; Thomas et al. 2015) (Fig. 14).

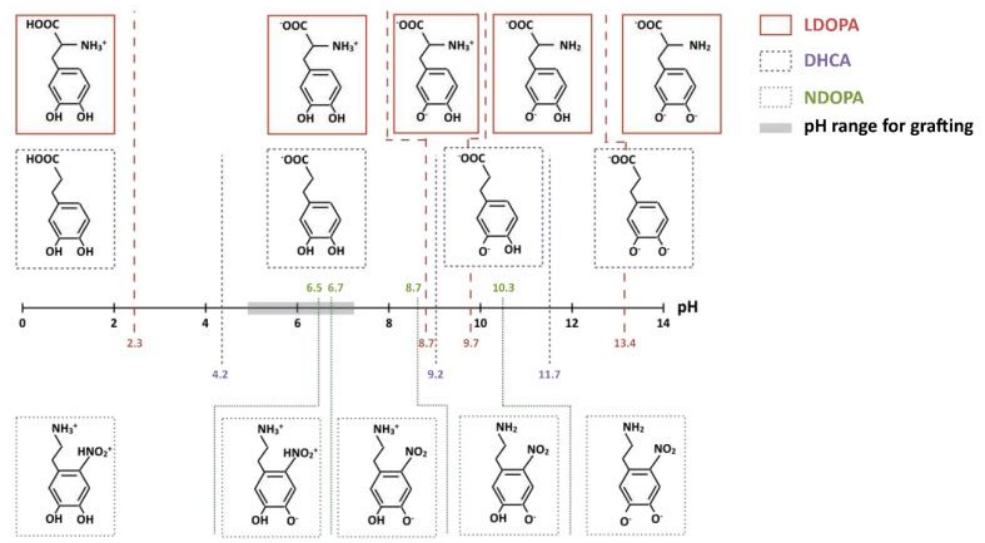


Catechol-based stabilizers can be grafted on TiONts: their presence can be proven by several characterization techniques such as FTIR, XPS, TGA. However, DHCA and LDOPA can transform into quinone at acidic $\mathrm{pH}$ and via oxidation or reduction reactions, limiting their grafting. $\mathrm{pH} 6$ seems the most suitable to avoid these phenomena, but to the detriment of a high grafting yield, due to a lower deprotonation of the hydroxyls of the catechol (Fig. 14). For all these reasons, NDOPA has aroused interest (Patil et al. 2018; Albu et al. 2019) as the use of this molecule allowed the oxidation process to be limited thanks to the close location of $\mathrm{NO}_{2}$ and $\mathrm{NH}_{2}$ groups. Furthermore, the grafting rate of NDOPA on TiONts can be improved in selecting the synthesis $\mathrm{pH}$ close to the pKa of both hydroxyls of LDOPA and DHCA. These can be proven by TGA with a more significant weight loss for TiONts-NDOPA. In addition, the characterizations carried out by IR and XPS showed a greater rate of formation of the Ti-O-catechol bond. Although, N. Millot et al. (Loiseau 2017) showed that grafting the NDOPA molecules on TiONts did not significantly improved the colloidal stability of TiONts-NDOPA under physiological conditions, it should be noted that TiONts with their elongated morphology and rather large size are often more difficult to stabilize than small spherical nanoparticles. Regardless, catecholbased coatings have proven their effectiveness in many cases such as substrates (Saiz-Poseu et al. 2019; Cheng et al. 2019) and nanoparticles $\left(\mathrm{TiO}_{2}, \mathrm{Fe}_{3} \mathrm{O}_{4}\right.$, etc.) (Benyettou et al. 2009; Motte et al. 2011; Guenin et al. 2014; Thapa et al. 2018; Mohammadi et al. 2020).

To conclude, catechol derivatives are great stabilizers in most situations and offer new possibilities of further graftings thanks to their amine or carboxylic acid moieties on them. When the criteria of colloidal stability are eventually not met, silanes and phosphonate pathways are excellent alternatives. Other options consist of additional polymer graftings such as polyethyleneglycol (PEG) or polysaccharide (chitosan for instance) derivatives as described in the following section.

\subsection{Other TiONts' surface modifications}

PEGylated chains grafted on nanoparticle (NP) surfaces lead to a charge shielding phenomenon (Maurizi et al. 2015), which enables to reduce the hepatic capture. Only a few studies are reporting the effect of PEGylated chain density and length on the biological behavior of TiONts and not much more on other metal oxide NPs (Gref et al. 2000; Gratton et al. 2008; Jokerst et al. 2011; Wu et al. 2020). It has been reported that higher PEG density and chain lengths improve the colloidal stability, reduce nonspecific adsorption of proteins and hence minimize the NP detection by the immune system, as well as their uptake by cells (Mosqueira et al. 2001; Cruje and Chithrani 2014). That is why the influence of different PEGylated chain lengths (HS-PEGn-COOH; $n=3,000 ; 5,000 ; 10,000$ ) on the colloidal stability of TiONts and on the $\mathrm{PEG}_{\mathrm{n}}$ density and conformation has been investigated by N. Millot et al. (Loiseau et al. 2020).

$\zeta$-potential measurements prove (Fig. 15) the presence of PEG $_{n}$ on the TiONts-APTES-surface via an important charge shielding for the different PEGylated chain lengths (the longer the chain, the most important the shielding). Colloidal stability was also investigated under physiological conditions (PBS $0.1 \mathrm{M}$; pH 7.4) by turbidimetric analyses (inset in Fig. 15) and correlated with TEM observations (Loiseau et al. 2020). The absorbance measurements as a function of time demonstrated a better colloidal stability for TiONts-APTES-PEG $n$ suspensions in than bare TiONts and TiONts-APTES without PEG. TGA results correlated with FT-IR and XPS analyses, prove the effective synthesis of TiONts-APTES$P E G_{n}$ nanohybrids. In particular, TGA analyses lead to $0.09 \mathrm{PEG}_{3,000} / \mathrm{nm}^{2} ; 0.05 \mathrm{PEG}_{5,000} / \mathrm{nm}^{2}$ and 0.03 $P E G_{10,000} / \mathrm{nm}^{2}$. These results reflect a relatively dense $P E G_{n}$ brush conformation. 


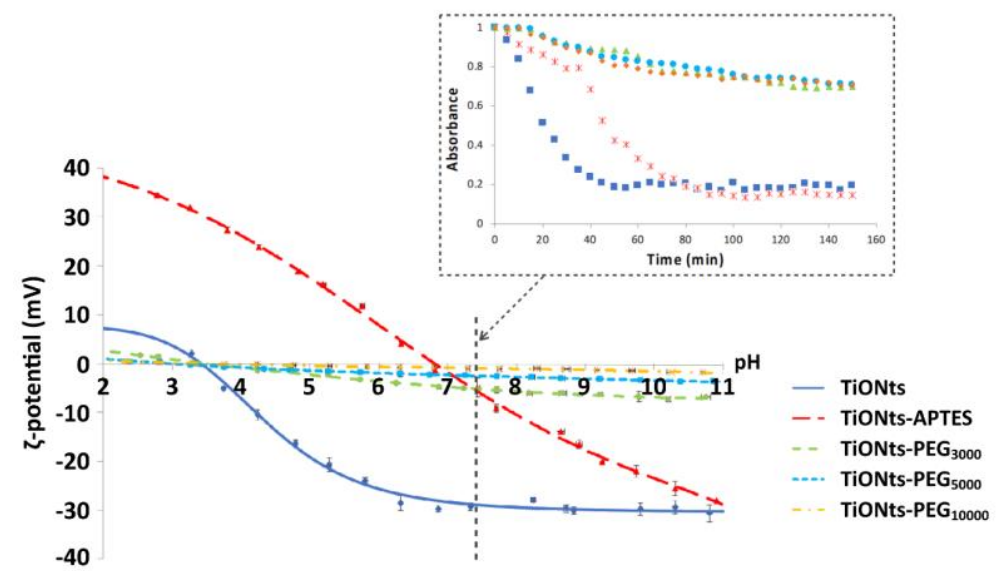

Fig. $15-\zeta$-potential curves as a function of $\mathrm{pH}$ in $\mathrm{NaCl}\left(10^{-2} \mathrm{M}\right)$ of bare TiONts and different functionalized-TiONts (the vertical dashed line corresponds to the physiological $\mathrm{pH}$ ). In inset, turbidimetric study: colloidal stability of functionalized-TiONts' suspensions (PBS $0.1 \mathrm{M}$; pH 7.4) over $150 \mathrm{~min}$ following their absorbance at $600 \mathrm{~nm}$ as a function of time

Chitosan (CT) has been also used to enhance the biocompatibility of hydrothermally synthesized nanotubes in a biological medium as substitute for polyethylene glycol that is generally used for biocompatibility. CT grafting was carried out using two different approaches; the first was made by a covalent bond using two intermediate molecules, and the second is based on electrostatic interactions between CT and TiONts (Fig. 16) (Sallem et al. 2017a). The type of elaborated linkage on the surface of TiONts was proven to influence the colloidal stability of the elaborated nanohybrids, which were studied in different media (Sallem et al. 2017a).
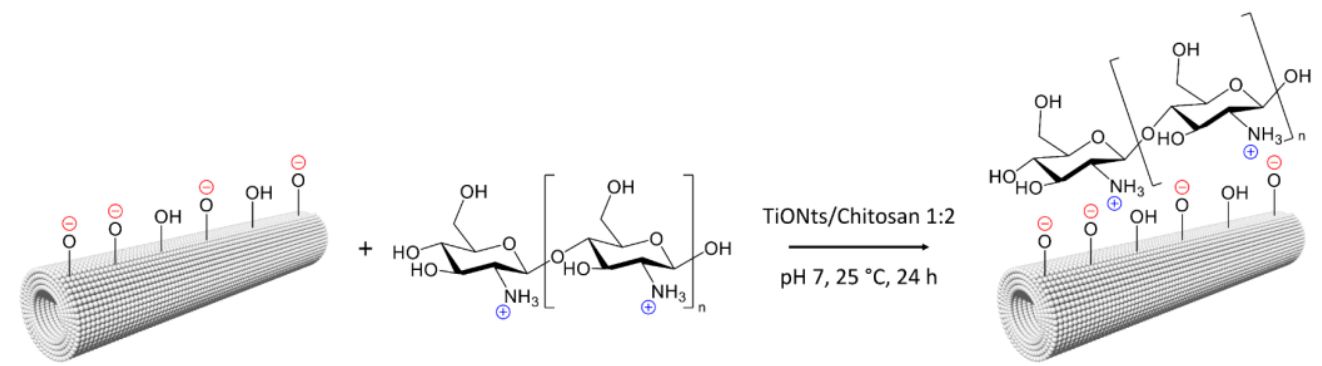

Fig. 16 - Surface modification of TiONts by chitosan showing the interaction between the TiONts' negatively-charged surface and positively-charged ammoniums of the chitosan polymer. The large number of dipolar interaction lead to stable chitosan-coated TiONts. 


\section{Theranostic applications of titanate nanotubes}

Regarding theranostic applications, a key feature of TiONts is their shape. Indeed, beyond composition and surface chemistry (a custom-engineered one according to the application), nanomaterial shape has a tremendous impact on nanoparticle-plasma protein interaction (Nel et al. 2009), margination (Blanco et al. 2015), biodistribution (Blanco et al. 2015) and cellular internalization pathways (Gratton et al. 2008). Thus, one can benefit from these unique tubular nanobiomaterials to (i) increase drug, nucleic acid, protein or imaging agent delivery, as well as (ii) improve the retention of the therapeutic or imaging modality at pathological site (Loiseau et al. 2017). This section explores the use of TiONts in the context of transfection, drug delivery, and radiotherapy monitored with medical imaging (theranostic).

\subsection{TiONts as new transfection agents}

The rationale behind using TiONts as a transfection agent was that neonatal cardiomyocytes (CM) are a highly challenging target for nucleic acid delivery (Papa et al. 2013). High transfection efficiencies are only achieved with the use of viral vectors as a mean of nucleic acid delivery (i.e. transduction). Conventional non-viral methods include liposomal delivery (Hunton et al. 2002; Lan et al. 2009) (such as Lipofectamine) and electroporation (Louch et al. 2011). However, liposomal delivery only achieves limited expression in this challenging CM model and electroporation represents a technical challenge in vivo. Because the internalization of tubular nanomaterials is often greater than their spherical counterparts (Gratton et al. 2008), there is thus potential to utilize this superior internalization of TiONts within CM. This could fill the current technological gap in non-viral nucleic acid delivery vehicles that achieve safe delivery but lack efficiency. Such a solution could provide non-viral methods that potentially address safety risks with viral techniques, in the context of clinical translation.

For this application, the negative charge of TiONts following their synthesis and purification to $\mathrm{pH} 6$ $\left(\xi=34.5 \mathrm{mV}\right.$ ) was reversed using polyethyleneimine $\left(\mathrm{PEI}, \mathrm{Mn} \sim 1,800 \mathrm{~g} \cdot \mathrm{mol}^{-1}\right)$ in order to complex the negatively charged plasmid DNA (linear pmaxGFP'M) at the tube surface, as well as provide the TiONts' suspension with greater stability and dispersion $(\xi=+39.0 \mathrm{mV}$ for both $1: 1$ and 1:10 TiONt:PEI w:w ratios) (Papa et al. 2013). TiONt-PEI-DNA complexes were formed in serum-free cell media to ensure no interference with plasma protein adsorption on the tube surface (i.e. protein corona) and the resulting net charge at the complex surface was $-21.0 \mathrm{mV}$ and $+25.0 \mathrm{mV}$ for 1:1 and 1:10 TiONt:PEI, respectively. These zeta potential values, coupled with a study of nanohybrid saturation of DNA via gel electrophoresis, confirmed that the two carriers had opposite net charge and that the 1:1 TiONt-PEIDNA was saturated in nucleic acids, compared to the 1:10 TiONt-PEI-DNA complex (that could potentially still increase its loading capacity). The positively charged 1:10 TiONt-PEI-DNA complex failed to achieve transfection, presumably due to a transient cytotoxicity observed solely for the high PEI load formulation as seen with LDH assays. In contrast and interestingly, the negatively charged complex lead to a successful transfection (i.e. $33 \%$ of CM population was GFP positive) 24-hours following a 5-hour incubation/transfection of the purified complexes with CM.

Compared to classical non-viral spherical nanoparticles, TiONts offer a new opportunity to mitigate the risks and challenges associated with the use of viral carriers for clinical translation.

\subsection{TiONts as new radiosensitizers}

One of the major challenges in radiation oncology is to get therapeutic effects in increasing the ionizing one while minimizing the administered doses whereas the dramatic side effects on healthy 
surrounding tissue should be minimized. TiONts are good candidates to induce a radiosensitizing effect (Mirjolet et al. 2013, 2017; Loiseau et al. 2019) - even though titanium has a low atomic number ( $\mathrm{Z}=22$ ) (Maezawa et al. 1996; Takakura 1996) - along with an absence of cytotoxicity (see section 4) (Mirjolet et al. 2013; Papa et al. 2013; Loiseau et al. 2017). N. Millot et al. studied the incubation of glioblastoma cell lines (SNB-19 and U87MG) with TiONts and under irradiation. The resulting clonogenic assays showed that radiosensitization is effective by TiONts at both low and high doses with a decrease in the $\mathrm{SF}_{2}$ parameter for both SNB-19 and U87MG cells. The latter is confirmed by an increase and decrease of $\alpha$ and $\beta$ parameters, respectively. Biological consequences could be explained by a decrease of DNA repair efficiency after irradiation and amplification of G2/M cell-cycle arrest (Boudon et al. 2014). Due to their shape, TiONts have the capability to be internalized in cells better than their spherical counterparts $\mathrm{TiO}_{2}$ (Papa et al. 2013). Moreover, after intratumoral injection, the oblong-shaped TiONts are maintained several days inside the tumor (more than $80 \%$ after $96 \mathrm{~h}$ by SPECT/CT imaging (Mirjolet et al. 2017) and more than $40 \%$ after 20 days by gamma counting (Loiseau et al. 2019)).
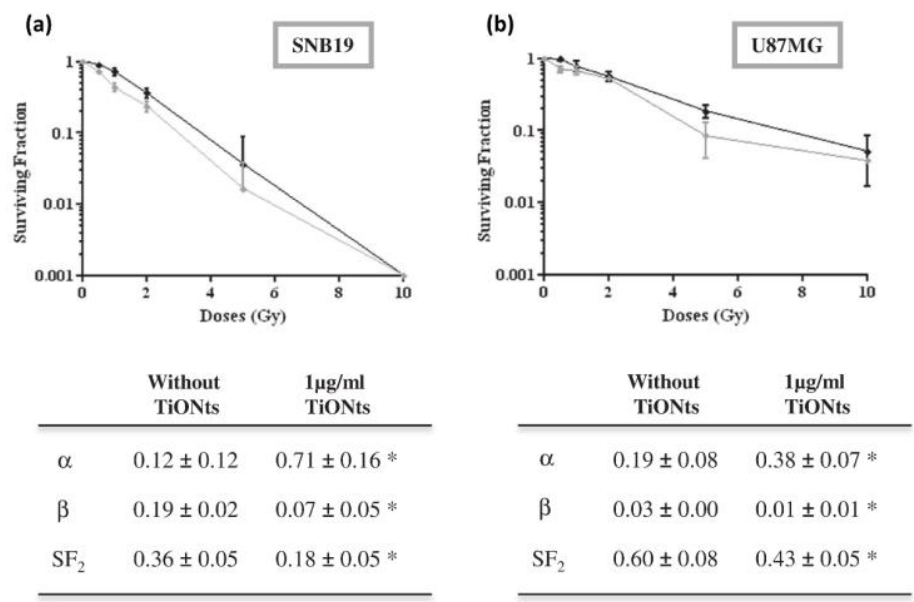

Fig. 17 - Survival fraction curves obtained from (a) SNB-19 and (b) U87MG both under the effect of X-Ray exposure without and with TiONts incubation $(1 \mu \mathrm{g} / \mathrm{mL})$. The radiosensitivity parameters obtained by a linear quadratic model ( $\alpha$ : initial slope, $\beta$ : degree of downward curvature and $\mathrm{SF}_{2}$ : survival fraction at $2 \mathrm{~Gy}$ ). According to (Mirjolet et al. 2013).

Thus, these nanomaterials are very interesting as therapeutic platform (intrinsic radiosensitizing properties, delivery of chemotherapeutic and radiotherapeutic agents in tumor sites). To promote TiONts to the theranostic level, superparamagnetic nanoparticles (iron oxide nanoparticles for example) can be associated to get detectable via MRI (magnetic resonance imaging) (Papa et al. 2011) while still benefiting from their radiosensitizing and shape properties.

\subsubsection{TiONts-DTX for the treatment of primary tumor}

Combining the ability of radiosensitization and concurrent chemotherapy is of great interest in an effort to improve current management of advanced prostate cancer. Thus, the combination between docetaxel (DTX), an anti-mitotic chemotherapy taxane-type drug, and TiONts has been investigated (Mirjolet et al. 2017; Loiseau et al. 2017, 2019). The idea is to increase the drug intracellular concentration by maintaining the tubes within the tumor, avoiding repeated injections that can result in chemotherapy resistance, several side effects for patients (Larsen et al. 2000; Parhi et al. 2012). A grafting strategy of TiONts carrying DTX has been developed by A. Loiseau et al. (Loiseau et al. 2017) and biological assays showed a satisfactory cytotoxic activity of the TiONt-DTX nanohydrid against two prostate cancer cell lines (PC-3 (Mirjolet et al. 2017) (Fig. 18a) and 22RV1 (Loiseau et al. 2017) for which $I_{50}$ is around $360-390 \mathrm{nM}$ ) when compared to that of free DTX (IC $\left.C_{50}: 2-4 \mathrm{nM}\right)$. Thereafter, the RT 
efficacy of these nanohybrids was also evaluated in vivo after intratumoral injection in PC-3 xenografted prostate tumors into Swiss nude mice (Mirjolet et al. 2017; Loiseau et al. 2017). The treatment with TiONts-DTX was significantly more effective than that with free DTX. Interestingly, mice treated with TiONts-DTX, without RT, exhibited a trend toward tumor growth delay compared with mice receiving free DTX ( 40 days vs. 30 days). Finally, tumor growth was significantly slowed down by TiONts-DTX associated with RT (three daily fractions of 4 Gy), compared with free DTX in the same conditions ( 73 days vs. 56 days to reach a tumor volume of $1,000 \mathrm{~mm}^{3}$, respectively) (Fig. 18b). These results suggest that TiONts-DTX noticeably improved RT efficacy and might enhance treatments of high-risk localized prostate cancers.

(a)

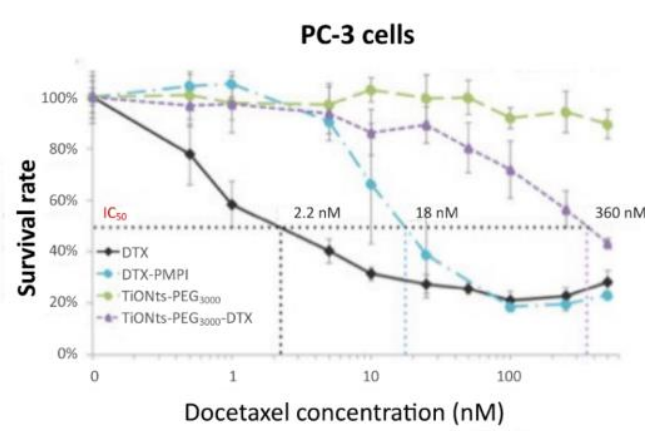

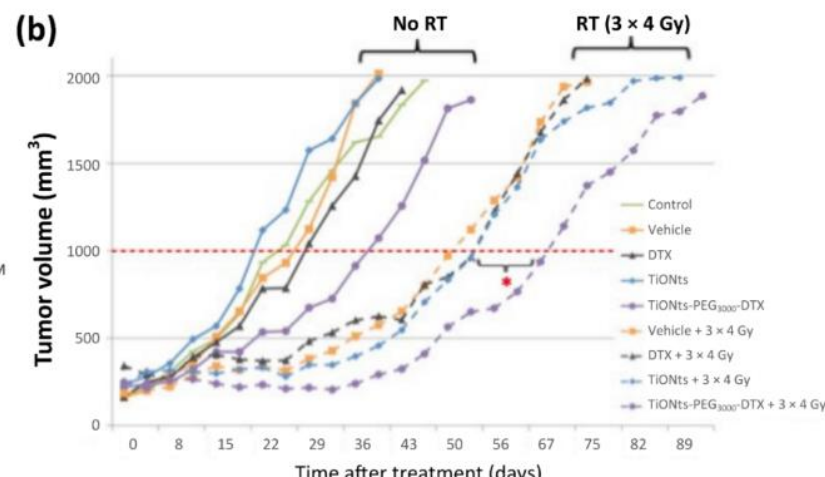

Time after treatment (days)

Fig. 18 - (a) MTS cytotoxicity assay on PC-3 human prostate cancer cell lines after incubation of DTX, modified-DTX, TiONts-PEG 3000 and TiONts-PEG 3000 -DTX. (b) Evaluation of therapeutic effect of vehicle, free DTX, free TiONts, and TiONts-DTX, associated or not with radiotherapy (RT) administered with three daily fractions of $4 \mathrm{~Gy}, 24 \mathrm{~h}$ after intratumoral injection into PC-3 xenografted tumors. Adapted and modified from (Mirjolet et al. 2017; Loiseau et al. 2017).

\subsubsection{TiONts-AuNPs-DTX as radiosensitizing agents}

The radiosensitizing effect of these nanohybrids has been further improved (when compared to the results presented in section 3.2.1) by grafting gold nanoparticles (Au@DTDTPA NPs) on TiONts. These Au@DTDTPA NPs are biologically well-tolerated and present a low toxicity (Miladi et al. 2014; Schuemann et al. 2016), they can improve the efficiency of radiation therapy by two-fold after intratumoral injection in animals (Miladi et al. 2014; Butterworth et al. 2016). However, their potential is probably under-exploited because of their fast renal clearance (Alric et al. 2013). Consequently, the association of Au@DTDTPA NPs with TiONts-DTX is expected to overcome this limitation by maintaining them on tumor sites after injection: the resulting TiONts-AuNPs-DTX nanohybrids were elaborated step-by-step A. Loiseau et al. (Loiseau et al. 2019). In vitro assays on a PC-3 human prostate cancer cell lines were performed (Fig. 19Erreur ! Source du renvoi introuvable.a) (Loiseau et al. 2019): Au@DTDTPA NPs and TiONts-AuNPs-PEG 3000 did not present any cytotoxicity while TiONts-AuNPs-PEG ${ }_{3000}$-DTX exhibited a greater cytotoxic activity compared to that observed for TiONts-DTX (IC 50 : $82 \mathrm{nM}$ vs. $360 \mathrm{nM}$, respectively). 

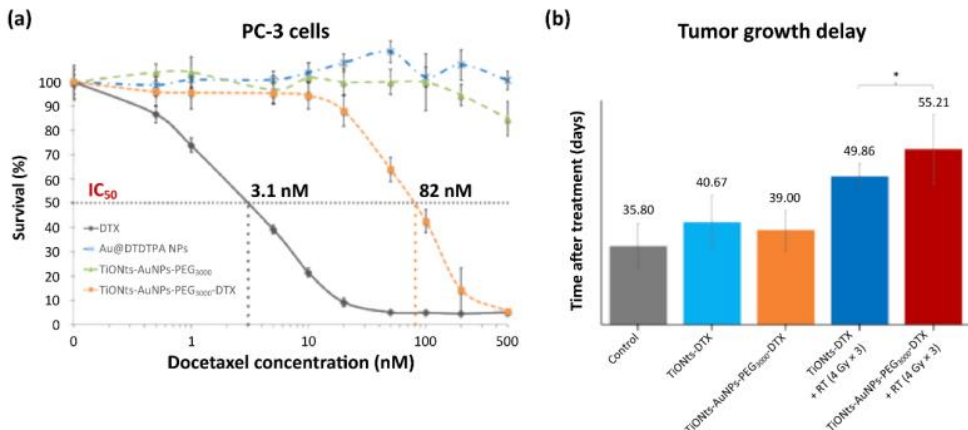

Fig. 19 - (a) MTS cytotoxicity assay on PC-3 human prostate cancer cell lines after incubation of DTX, Au@DTDTPA NPs, TiONts-AuNPs-PEG3000 and TiONts-AuNPs-PEG3000-DTX. (b) Evaluation of therapeutic effect of control, TiONts-DTX and TiONts-AuNPs-PEG3000-DTX, associated or not with radiotherapy (RT) administered with three daily fractions of $4 \mathrm{~Gy}$, $24 \mathrm{~h}$ after intratumoral injection into PC-3 xenografted tumors. Adapted from (Loiseau et al. 2019).

Finally, the synergistic combination between TiONts, DTX and AuNPs in the same entity with RT showed a better therapeutic efficacy by fulfilling their role as carriers and concentrating the radiotherapeutic and chemotherapeutic agents (Fig. 19Erreur! Source du renvoi introuvable.b). Indeed, tumor growth was significantly slowed down $(p=0.035)$ by the treatment of TiONts-AuNPs-PEG ${ }_{3000}$-DTX + RT ( 55 days to reach a tumor volume of $1,000 \mathrm{~mm}^{3}$ ), compared with TiONts-DTX + RT (50 days) in the same conditions. The elaborated design asserts TiONt-based nanohybrids to be an attractive, and versatile platform for the treatment of prostate cancer.

\subsection{TiONts as new nanocarriers}

In 2016, T. Baati et al. have shown the effectiveness of a TiONt-based nanocarrier against glioblastoma multiform with a controlled administration of genistein (biologically active flavonoid) in glioblastoma cells (Baati et al. 2016). This study showed that these TiONts have a drug loading efficiency of $51.2 \mathrm{wt} \%$ and allows a controlled release of the therapeutic agent. F. Sallem et al. have developed the nanocarrier of a therapeutic molecule: a stilbene phenol, 4'-hydroxy-4-(3-aminopropoxy)-transstilbene (HAPtS), which is a trans-resveratrol derivative. Trans-resveratrol is a natural stilbenic polyphenol, known to prevent or slow down number of diseases including cardiovascular ones (Hung et al. 2000) and cancer (Baur and Sinclair 2006) because of its anti-inflammatory (Xiao et al. 2013), antiviral, antitumor and antifungal properties (Pirola and Froejdoe 2008). Despite all the interesting biological properties of trans-resveratrol, its low bioavailability and solubility (Lu et al. 2009), its rapid metabolism and its rapid elimination in the urine remain its major limitations. The grafting of this molecule on TiONts' surface can circumvent these limitations.

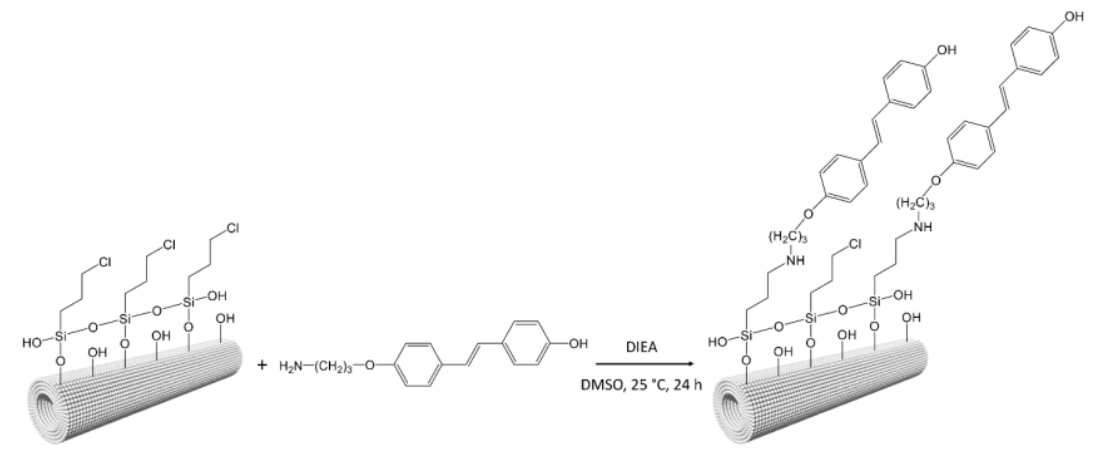

Fig. 20 - Scheme of the grafting of the stilbene compound on the surface of TiONts via a spacer

After pre-functionalization with 3-chloropropyltriethoxysilane (CPTES), the stilbenic phenol (HAPtS) was successfully grafted onto TiONts-CPTES surface using a condensation reaction between HAPtS and 
CPTES through nucleophilic substitution. The resulting grafting rate was of about $72.5 \mathrm{mg} / \mathrm{g}$ of TiONts (Sallem 2017). 


\section{Biosafety and nanotoxicity of TiONts}

This section intends to discuss the internalization pathways of TiONts, as well as summarize some of the subsequent key aspects of TiONts' cytotoxicity profile that have been discovered thus far (Maurizi et al. 2018).

In early studies, TiONts have been detected inside vacuoles of SNB-19 and U87MG cells suggesting an internalization via endocytosis/macropinocytosis. In parallel, TiONts were also seen penetrating the plasma membrane, suggesting their diffusion through the lipidic bilayer (Mirjolet et al. 2013). Further studies have confirmed this diffusion phenomena as TiONts were still detected within murine microglial BV-2 cells despite their incubation with the endocytosis inhibitor amiloride (Sruthi et al. 2018). These observations are in agreement with what has been described regarding the internalization pathways of carbon nanotubes (Raffa et al. 2009). Once they cross the plasma membrane, nanoparticles can potentially induce cellular stress, or even cell death, depending on multiple physico-chemical factors that modulate their (cyto)toxicity or safety profile (i.e. chemical composition, nanoparticle surface engineering, intracellular concentration). Thus, each TiONts' formulation (depending on the specific synthesis parameters, see section 1) need to be assessed within the relevant physiological in vitro or in vivo models. For example, Magrez et al. demonstrated that titanate-based nanofilaments have different levels of cytotoxicity in regards to H596 lung carcinoma cells, depending on their chemical composition (Magrez et al. 2009). Specifically, the post-synthesis acidic treatment used (to substitute $\mathrm{Na}^{+}$by $\mathrm{H}^{+}$) generated a composition that was more cytotoxic to H596 cells as compared to non-acid treated filament counterparts (Magrez et al. 2009). This illustrates the complexity and multifaceted behavior of these biomaterials. As previously said, Papa et al. evaluated the cytotoxicity of bare (and non-acid treated) TiONts, TiONts-PEI as well as their spherical counterpart $\mathrm{P} 25 \mathrm{TiO}_{2}$ in regards to neonatal cardiomyocytes via MTT assay (Papa et al. 2013). No apparent cytotoxicity was detected within the range of concentrations tested (up to $10 \mu \mathrm{g} / \mathrm{mL}$ ) at 24 hours (Papa et al. 2013). In addition, up to $100 \mu \mathrm{g} / \mathrm{mL}$ TiONts did not induce significant cytotoxicity towards SNB-19 and U87MG cell lines at 72 hours, as measured by cell proliferation assay (Mirjolet et al. 2013). Overall, the mechanism of diffusion of the TiONts across the cell membrane does not appear to affect cell viability in multiple cell lines, despite inducing transient lipid bilayer disruption.

Microglial activation and associated oxidative burst are major challenges in drug delivery applications across the brain (Bussy et al. 2015). In this context, TiONts-APTES have been evaluated in vitro using murine microglial BV-2 cells (Sruthi et al. 2018). TiONts-APTES exposure (from $5 \mu \mathrm{g} / \mathrm{mL}$ up to $80 \mu \mathrm{g} / \mathrm{mL}$ of TiONts-APTES for $24 \mathrm{~h}$ ) lead to an increased ROS production and transient mitochondrial hyperpolarization. Furthermore, the TiONts-APTES showed good biocompatibility on BV-2 cells as revealed by the plasma membrane integrity, lysosomal membrane integrity, morphology, and viability analysis.

The toxicity assessment on the zebrafish embryo model is a very recent and interesting method for the in vivo screening of nanoparticles. This test analyzes toxicity in a much more complex system than cultured cells. It is a less expensive test than large-scale biocompatibility studies in mice or rats (Rizzo et al. 2013). Zebrafish embryos are transparent and develop outside their mother, making it easy to follow and understand the cellular mechanism using a simple light microscope. TiONts-chitosan nanohybrid developed in section 2.4 have been evaluated with concentrations varying from 1 to $100 \mu \mathrm{g} / \mathrm{mL}$. The survival, hatching and development of zebrafish were monitored for $96 \mathrm{~h}$. The survival of zebrafish must be close to $100 \%$, hatching greater than $90 \%$ (between 24 and 48 hours) and the larval malformations close to $0 \%$ conclude on the non-toxicity of nanohybrids. The survival and hatching of zebrafish are not affected by the presence of nanohybrids for the entire concentration range studied from 1 to $100 \mu \mathrm{g} / \mathrm{mL}$ (Fig. 21). No lethality or morphological change was observed even for the highest concentrations. This confirms the non-toxicity of TiONts modified by chitosan. 


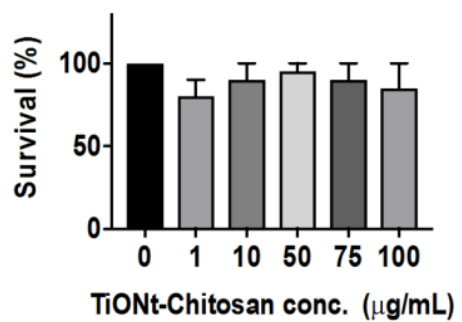

(a)

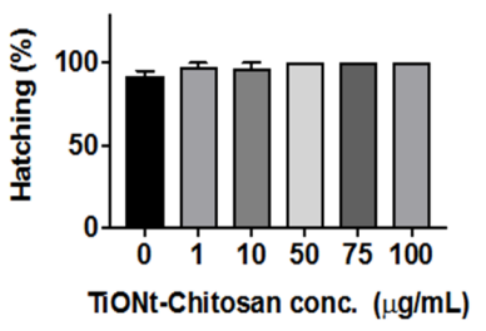

(b)

Fig. 21 - Percentage of (a) embryo survival and (b) hatching of zebrafish eggs as a function of TiONts-CT concentration. The number of repetitions is three $(n=3)$ and 60 embryos are used in each repetition (therefore 180 animals in total)

In these models, TiONts show a good safety profile within the relevant concentrations and doses tested. Nonetheless, further studies including the interaction of TiONts with immune cells, blood cells and plasma proteins, will allow a better understanding of the biological behavior and fate of these bioengineered materials.

\section{Conclusions}

The aim of this chapter was to illustrate the potential of titanate nanotubes as new potent tools for nanomedicine. The difficulties encountered during their synthesis as well as the different strategies for their necessary surface modification have been illustrated, always via a step-by-step approach. Several bioapplications of these engineered TiONts have been outlined: nanocarriers of plasmid DNA or of transresveratrol derivatives, radiosensitizers etc. TiONts have also shown a good safety profile in all the bioassays developed to evaluate their potential toxicity. Finally, these functionalized TiONts appear as promising versatile tools in the biomedical field to fight some diseases such as cancer. In this context and for these elongated inorganic nanoparticles, intratumoral injection seem to be a relevant way of administration.

\section{Acknowledgments}

$J B, A L, F S, L M$ and NM acknowledge the funding support from French Government through the CNRS, the "Université de Bourgogne", the "Conseil Régional Bourgogne Franche-Comté, the European Union (PO FEDER-FSE Bourgogne 2014/2020 programs) and the Cancéropôle Est and Graduate School EUREIPHI (17-EURE-0002). ALP acknowledges the support from the George Washington University startup funds. All the people who contributed in the results presented in this chapter are greatly acknowledged: Sudhakaran Sruthi, Gérard Lizard, Thomas Courant, Johanna Chluba, Laurence Motte, Erwan Guénin, Frédéric Geinguenaud, Laure Dumond, David Vandroux, Céline Mirjolet, Véronique Morgand, Olivier Heintz and Rémi Chassagnon, as well as all the people from the Pharmlmage ${ }^{\circledR}$ consortium, the $3 \mathrm{MIM}$ agreement and the IMAPPI program who are involved but not mentioned in the presented results.

\section{Bibliography}

Agarwal R, Jurney P, Raythatha M, et al (2015) Effect of Shape, Size, and Aspect Ratio on Nanoparticle Penetration and Distribution inside Solid Tissues Using 3D Spheroid Models. Adv Healthc Mater 4:2269-2280. https://doi.org/10.1002/adhm.201500441 
Albu AM, Draghicescu W, Munteanu T, et al (2019) Nitrodopamine vs dopamine as an intermediate layer for bone regeneration applications. Mater Sci Eng C 98:461-471. https://doi.org/10.1016/j.msec.2019.01.014

Alric C, Miladi I, Kryza D, et al (2013) The biodistribution of gold nanoparticles designed for renal clearance. Nanoscale 5:5930-5939. https://doi.org/10.1039/c3nr00012e

Amstad E, Gehring AU, Fischer H, et al (2011a) Influence of Electronegative Substituents on the Binding Affinity of Catechol-Derived Anchors to Fe304 Nanoparticles. J Phys Chem C 115:683-691. https://doi.org/10.1021/jp1109306

Amstad E, Gillich T, Bilecka I, et al (2009) Ultrastable iron oxide nanoparticle colloidal suspensions using dispersants with catechol-derived anchor groups. Nano Lett 9:4042-4048. https://doi.org/10.1021/nl902212q

Amstad E, Textor M, Reimhult E (2011b) Stabilization and functionalization of iron oxide nanoparticles for biomedical applications. Nanoscale 3:2819-2843. https://doi.org/10.1039/c1nr10173k

Awan UA, Ali S, Rehman M, et al (2018) Stable and reproducible synthesis of gold nanorods for biomedical applications: a comprehensive study. IET Nanobiotechnol 12:182-190. https://doi.org/10.1049/iet-nbt.2016.0220

Baati T, Kefi BB, Aouane A, et al (2016) Biocompatible titanate nanotubes with high loading capacity of genistein: cytotoxicity study and anti-migratory effect on U87-MG cancer cell lines. Rsc Adv 6:101688-101696. https://doi.org/10.1039/c6ra24569b

Bahri S, Jonsson CM, Jonsson CL, et al (2011) Adsorption and Surface Complexation Study of L-DOPA on Rutile (alpha-TiO2) in $\mathrm{NaCl}$ Solutions. Environ Sci Technol 45:3959-3966. https://doi.org/10.1021/es1042832

Balasundaram G, Sato M, Webster TJ (2006) Using hydroxyapatite nanoparticles and decreased crystallinity to promote osteoblast adhesion similar to functionalizing with RGD. Biomaterials 27:2798-2805. https://doi.org/10.1016/j.biomaterials.2005.12.008

Baur JA, Sinclair DA (2006) Therapeutic potential of resveratrol: the in vivo evidence. Nat Rev Drug Discov 5:493-506. https://doi.org/10.1038/nrd2060

Bavykin DV, Friedrich JM, Walsh FC (2006) Protonated titanates and TiO2 nanostructured materials: Synthesis, properties, and applications. Adv Mater 18:2807-2824. https://doi.org/10.1002/adma.200502696

Bavykin DV, Walsh FC (2009) Elongated Titanate Nanostructures and Their Applications. Eur J Inorg Chem 2009:977-997. https://doi.org/10.1002/ejic.200801122

Bellat V, Chassagnon R, Heintz $O$, et al (2015) A multi-step mechanism and integrity of titanate nanoribbons. Dalton Trans 44:1150-1160. https://doi.org/10.1039/c4dt02573c

Benyettou F, Lalatonne $\mathrm{Y}$, Chebbi I, et al (2011) A multimodal magnetic resonance imaging nanoplatform for cancer theranostics. Phys Chem Chem Phys 13:10020-10027. https://doi.org/10.1039/c0cp02034f

Benyettou F, Lalatonne Y, Sainte-Catherine O, et al (2009) Superparamagnetic nanovector with anticancer properties: gamma Fe2O3@Zoledronate. Int J Pharm 379:324-327. https://doi.org/10.1016/j.ijpharm.2009.04.010

Bianco A, Kostarelos K, Prato M (2005) Applications of carbon nanotubes in drug delivery. Curr Opin Chem Biol 9:674-679. https://doi.org/10.1016/j.cbpa.2005.10.005

Blanco E, Shen H, Ferrari M (2015) Principles of nanoparticle design for overcoming biological barriers to drug delivery. Nat Biotechnol 33:941-951. https://doi.org/10.1038/nbt.3330

Boudon J, Papa A-L, Paris J, Millot N (2014) Titanate Nanotubes as a Versatile Platform for Nanomedicine. In: Nanomedicine. One Central Press (OCP), pp 403-428

Bussy C, Al-Jamal KT, Boczkowski J, et al (2015) Microglia Determine Brain Region-Specific Neurotoxic Responses to Chemically Functionalized Carbon Nano tubes. Acs Nano 9:7815-7830. https://doi.org/10.1021/acsnano.5b02358

Butterworth KT, Nicol JR, Ghita M, et al (2016) Preclinical evaluation of gold-DTDTPA nanoparticles as theranostic agents in prostate cancer radiotherapy. Nanomed 11:2035-2047. https://doi.org/10.2217/nnm-2016-0062 
Campos CH, Diaz CF, Guzman JL, et al (2016) PAMAM-Conjugated Alumina Nanotubes as Novel Noncytotoxic Nanocarriers with Enhanced Drug Loading and Releasing Performances. Macromol Chem Phys 217:1712-1722. https://doi.org/10.1002/macp.201600136

Cheng YF, Zhang JY, Wang YB, et al (2019) Deposition of catechol-functionalized chitosan and silver nanoparticles on biomedical titanium surfaces for antibacterial application. Mater Sci Eng C 98:649-656. https://doi.org/10.1016/j.msec.2019.01.019

Cruje C, Chithrani DB (2014) Polyethylene Glycol Density and Length Affects Nanoparticle Uptake by Cancer Cells. J Nanomedicine Res Volume 1: https://doi.org/10.15406/jnmr.2014.01.00006

Daou TJ, Buathong S, Ung D, et al (2007) Investigation of the grafting rate of organic molecules on the surface of magnetite nanoparticles as a function of the coupling agent. Sens Actuators B-Chem 126:159-162. https://doi.org/10.1016/j.snb.2006.11.020

Das R, Alonso J, Nemati Porshokouh Z, et al (2016) Tunable High Aspect Ratio Iron Oxide Nanorods for Enhanced Hyperthermia. J Phys Chem C 120:10086-10093. https://doi.org/10.1021/acs.jpcc.6b02006

Decuzzi P, Coclite A, Lee A, et al (2017) Nano-Particles for Biomedical Applications. In: Bhushan B (ed) Springer Handbook of Nanotechnology. Springer, Berlin, Heidelberg, pp 643-691

Deng ZJ, Mortimer G, Schiller T, et al (2009) Differential plasma protein binding to metal oxide nanoparticles. Nanotechnology 20:455101. https://doi.org/10.1088/09574484/20/45/455101

Ernsting MJ, Murakami M, Roy A, Li S-D (2013) Factors Controlling the Pharmacokinetics, Biodistribution and Intratumoral Penetration of Nanoparticles. J Control Release Off J Control Release Soc 172:782-794. https://doi.org/10.1016/j.jconrel.2013.09.013

Ge X, Ren C, Lu X, et al (2019) Surfactant-free electrochemical synthesis of fluoridated hydroxyapatite nanorods for biomedical applications. Ceram Int 45:17336-17343. https://doi.org/10.1016/j.ceramint.2019.05.292

Gong D, Grimes CA, Varghese OK, et al (2001) Titanium oxide nanotube arrays prepared by anodic oxidation. J Mater Res 16:3331-3334. https://doi.org/10.1557/JMR.2001.0457

Gratton SEA, Ropp PA, Pohlhaus PD, et al (2008) The effect of particle design on cellular internalization pathways. Proc Natl Acad Sci U S A 105:11613-11618. https://doi.org/10.1073/pnas.0801763105

Gref R, Luck M, Quellec P, et al (2000) "Stealth" corona-core nanoparticles surface modified by polyethylene glycol (PEG): influences of the corona (PEG chain length and surface density) and of the core composition on phagocytic uptake and plasma protein adsorption. Colloids Surf BBiointerfaces 18:301-313. https://doi.org/10.1016/S0927-7765(99)00156-3

Guenin E, Lalatonne Y, Bolley J, et al (2014) Catechol versus bisphosphonate ligand exchange at the surface of iron oxide nanoparticles: towards multi-functionalization. J Nanoparticle Res 16:2596. https://doi.org/10.1007/s11051-014-2596-7

Guerrero G, Alauzun JG, Granier M, et al (2013) Phosphonate coupling molecules for the control of surface/interface properties and the synthesis of nanomaterials. Dalton Trans 42:1256912585. https://doi.org/10.1039/c3dt51193f

Guerrero G, Mutin PH, Vioux A (2001) Anchoring of phosphonate and phosphinate coupling molecules on titania particles. Chem Mater 13:4367-4373. https://doi.org/10.1021/cm001253u

Hahm J (2016) Fundamental Properties of One-Dimensional Zinc Oxide Nanomaterials and Implementations in Various Detection Modes of Enhanced Biosensing. In: Johnson MA, Martinez TJ (eds) Annual Review of Physical Chemistry, Vol 67. Annual Reviews, Palo Alto, pp 691-717

Howarter JA, Youngblood JP (2006) Optimization of silica silanization by 3-aminopropyltriethoxysilane. Langmuir 22:11142-11147. https://doi.org/10.1021/la061240g

Hung LM, Chen JK, Huang SS, et al (2000) Cardioprotective effect of resveratrol, a natural antioxidant derived from grapes. Cardiovasc Res 47:549-555. https://doi.org/10.1016/S00086363(00)00102-4 
Hunton DL, Lucchesi PA, Pang Y, et al (2002) Capacitative calcium entry contributes to nuclear factor of activated T-cells nuclear translocation and hypertrophy in cardiomyocytes. J Biol Chem 277:14266-14273. https://doi.org/10.1074/jbc.M107167200

Jeong E, UI Kim C, Byun J, et al (2020) Quantitative evaluation of the antibacterial factors of ZnO nanorod arrays under dark conditions: Physical and chemical effects on Escherichia coil inactivation. Sci Total Environ 712:136574. https://doi.org/10.1016/j.scitotenv.2020.136574

Jokerst JV, Lobovkina T, Zare RN, Gambhir SS (2011) Nanoparticle PEGylation for imaging and therapy. Nanomed 6:715-728. https://doi.org/10.2217/nnm.11.19

Kasuga T, Hiramatsu M, Hoson A, et al (1998) Formation of titanium oxide nanotube. Langmuir 14:3160-3163. https://doi.org/10.1021/la9713816

Kostarelos K, Lacerda L, Pastorin G, et al (2007) Cellular uptake of functionalized carbon nanotubes is independent of functional group and cell type. Nat Nanotechnol 2:108-113. https://doi.org/10.1038/nnano.2006.209

Lan X, Yin X, Wang R, et al (2009) Comparative study of cellular kinetics of reporter probe [131I]FIAU in neonatal cardiac myocytes after transfer of HSV1-tk reporter gene with two vectors. Nucl Med Biol 36:207-213. https://doi.org/10.1016/j.nucmedbio.2008.10.016

Larsen AK, Escargueil AE, Skladanowski A (2000) Resistance mechanisms associated with altered intracellular distribution of anticancer agents. Pharmacol Ther 85:217-229. https://doi.org/10.1016/S0163-7258(99)00073-X

Lee KW, Kim YJ, Kim DO, et al (2003) Major phenolics in apple and their contribution to the total antioxidant capacity. J Agric Food Chem 51:6516-6520. https://doi.org/10.1021/jf034475w

Lee N, Hummer DR, Sverjensky DA, et al (2012) Speciation of L-DOPA on Nanorutile as a Function of $\mathrm{pH}$ and Surface Coverage Using Surface-Enhanced Raman Spectroscopy (SERS). Langmuir 28:17322-17330. https://doi.org/10.1021/la303607a

Liu Y, Li Y, Li X-M, He T (2013) Kinetics of (3-Aminopropyl)triethoxylsilane (APTES) Silanization of Superparamagnetic Iron Oxide Nanoparticles. Langmuir 29:15275-15282. https://doi.org/10.1021/la403269u

Loiseau A (2017) Nanotubes de titanate comme nanovecteurs polyvalents : radiosensibilisants du cancer de la prostate et sondes pour l'imagerie nucléaire. Theses, Université Bourgogne Franche-Comté

Loiseau A, Boudon J, Mirjolet C, et al (2017) Taxane-Grafted Metal-Oxide Nanoparticles as a New Theranostic Tool against Cancer: The Promising Example of Docetaxel-Functionalized Titanate Nanotubes on Prostate Tumors. Adv Healthc Mater 6:. https://doi.org/10.1002/adhm.201700245

Loiseau A, Boudon J, Mirjolet C, et al (2020) The influence of the PEGylated length on titanate nanotubes properties and docetaxel nanohybrid cytotoxicity against prostate cancer cells. Molecules submitted

Loiseau A, Boudon J, Oudot A, et al (2019) Titanate Nanotubes Engineered with Gold Nanoparticles and Docetaxel to Enhance Radiotherapy on Xenografted Prostate Tumors. Cancers 11:1962. https://doi.org/10.3390/cancers11121962

Louch WE, Sheehan KA, Wolska BM (2011) Methods in cardiomyocyte isolation, culture, and gene transfer. J Mol Cell Cardiol 51:288-298. https://doi.org/10.1016/j.yjmcc.2011.06.012

Lu Z, Cheng B, Hu Y, et al (2009) Complexation of resveratrol with cyclodextrins: Solubility and antioxidant activity. Food Chem 113:17-20. https://doi.org/10.1016/j.foodchem.2008.04.042

Ma H, Tarr J, DeCoster MA, et al (2009) Synthesis of magnetic porous hollow silica nanotubes for drug delivery. J Appl Phys 105:07B309. https://doi.org/10.1063/1.3072048

Maezawa H, Furusawa Y, Kobayashi K, et al (1996) Lethal effect of K-shell absorption of intracellular phosphorus on wild-type and radiation sensitive mutants of Escherichia coli. Acta Oncol 35:889-894. https://doi.org/10.3109/02841869609104042

Magrez A, Horváth L, Smajda R, et al (2009) Cellular Toxicity of TiO2-Based Nanofilaments. ACS Nano 3:2274-2280. https://doi.org/10.1021/nn9002067 
Maurizi L, Papa A-L, Boudon J, et al (2018) Toxicological Risk Assessment of Emerging Nanomaterials: Cytotoxicity, Cellular Uptake, Effects on Biogenesis and Cell Organelle Activity, Acute Toxicity and Biodistribution of Oxide Nanoparticles. In: Gomes AC, Sarria MP (eds) Unraveling the Safety Profile of Nanoscale Particles and Materials - From Biomedical to Environmental Applications, Andreia C. Gomes and Marisa P. Sarria. InTech, Rijeka, pp 17-36

Maurizi L, Papa A-L, Dumont L, et al (2015) Influence of Surface Charge and Polymer Coating on Internalization and Biodistribution of Polyethylene Glycol-Modified Iron Oxide Nanoparticles. J Biomed Nanotechnol 11:126-136. https://doi.org/10.1166/jbn.2015.1996

Miladi I, Alric C, Dufort S, et al (2014) The In Vivo Radiosensitizing Effect of Gold Nanoparticles Based MRI Contrast Agents. Small 10:1116-1124. https://doi.org/10.1002/smll.201302303

Mirjolet C, Boudon J, Loiseau A, et al (2017) Docetaxel-titanate nanotubes enhance radiosensitivity in an androgen-independent prostate cancer model. Int J Nanomedicine 12:6357-6364. https://doi.org/10.2147/IJN.S139167

Mirjolet C, Papa AL, Créhange G, et al (2013) The radiosensitization effect of titanate nanotubes as a new tool in radiation therapy for glioblastoma: A proof-of-concept. Radiother Oncol J Eur Soc Ther Radiol Oncol. https://doi.org/10.1016/j.rad onc.2013 .04.004

Mohammadi F, Moeeni M, Li C, et al (2020) Interaction of cellulose and nitrodopamine coated superparamagnetic iron oxide nanoparticles with alpha-lactalbumin. RSC Adv 10:9704-9716. https://doi.org/10.1039/C9RA09045B

Mosqueira VCF, Legrand P, Morgat JL, et al (2001) Biodistribution of long-circulating PEG-grafted nanocapsules in mice: Effects of PEG chain length and density. Pharm Res 18:1411-1419. https://doi.org/10.1023/A:1012248721523

Motte L, Benyettou F, de Beaucorps C, et al (2011) Multimodal superparamagnetic nanoplatform for clinical applications: immunoassays, imaging \& therapy. Faraday Discuss 149:211-225. https://doi.org/10.1039/c005286h

Mutin PH, Guerrero G, Vioux A (2005) Hybrid materials from organophosphorus coupling molecules. J Mater Chem 15:3761-3768. https://doi.org/10.1039/b505422b

Nel AE, Mädler L, Velegol D, et al (2009) Understanding biophysicochemical interactions at the nanobio interface. Nat Mater 8:543-557. https://doi.org/10.1038/nmat2442

Niu L, Shao M, Wang S, et al (2008) Titanate nanotubes: preparation, characterization, and application in the detection of dopamine. J Mater Sci 43:1510-1514. https://doi.org/10.1007/s10853-0072374-3

Papa A-L, Boudon J, Bellat V, et al (2015) Dispersion of titanate nanotubes for nanomedicine: comparison of PEI and PEG nanohybrids. Dalton Trans Camb Engl 2003 44:739-746. https://doi.org/10.1039/c4dt02552k

Papa A-L, Dumont L, Vandroux D, Millot N (2013) Titanate nanotubes: towards a novel and safer nanovector for cardiomyocytes. Nanotoxicology 7:1131-1142. https://doi.org/10.3109/17435390.2012.710661

Papa A-L, Maurizi L, Vandroux D, et al (2011) Synthesis of Titanate Nanotubes Directly Coated with USPIO in Hydrothermal Conditions: A New Detectable Nanocarrier. J Phys Chem C 115:1901219017. https://doi.org/10.1021/jp2056893

Papa A-L, Millot N, Saviot L, et al (2009) Effect of Reaction Parameters on Composition and Morphology of Titanate Nanomaterials. J Phys Chem C 113:12682-12689. https://doi.org/10.1021/jp903195h

Parhi P, Mohanty C, Sahoo SK (2012) Nanotechnology-based combinational drug delivery: an emerging approach for cancer therapy. Drug Discov Today 17:1044-1052. https://doi.org/10.1016/j.drudis.2012.05.010

Paris J, Bernhard Y, Boudon J, et al (2015) Phthalocyanine-titanate nanotubes: a promising nanocarrier detectable by optical imaging in the so-called imaging window. Rsc Adv 5:6315-6322. https://doi.org/10.1039/c4ra13988g 
Patil N, Jérôme C, Detrembleur C (2018) Recent advances in the synthesis of catechol-derived (bio)polymers for applications in energy storage and environment. Prog Polym Sci 82:34-91. https://doi.org/10.1016/j.progpolymsci.2018.04.002

Pirola L, Froejdoe S (2008) Resveratrol: One molecule, many targets. lubmb Life 60:323-332. https://doi.org/10.1002/iub.47

Pontón PI, d'Almeida JRM, Marinkovic BA, et al (2014) The effects of the chemical composition of titanate nanotubes and solvent type on 3-aminopropyltriethoxysilane grafting efficiency. Appl Surf Sci 301:315-322. https://doi.org/10.1016/j.apsusc.2014.02.071

Pujari SP, Scheres L, Marcelis ATM, Zuilhof H (2014) Covalent Surface Modification of Oxide Surfaces. Angew Chem-Int Ed 53:6322-6356. https://doi.org/10.1002/anie.201306709

Raffa V, Ciofani G, Vittorio O, et al (2009) Physicochemical properties affecting cellular uptake of carbon nanotubes. Nanomed 5:89-97. https://doi.org/10.2217/nnm.09.95

Ries H, Cook H (1954) Monomolecular Films of Mixtures .1. Stearic Acid with Isostearic Acid and with Tri-Para-Cresyl Phosphate - Comparison of Components with Octadecylphosphonic Acid and with Tri-Ortho-Xenyl Phosphate. J Colloid Sci 9:535-546. https://doi.org/10.1016/00958522(54)90056-2

Rizzo LY, Golombek SK, Mertens ME, et al (2013) In Vivo Nanotoxicity Testing using the Zebrafish Embryo Assay. J Mater Chem B Mater Biol Med 1:. https://doi.org/10.1039/C3TB20528B

Saiz-Poseu J, Mancebo-Aracil J, Nador F, et al (2019) The Chemistry behind Catechol-Based Adhesion. Angew Chem Int Ed 58:696-714. https://doi.org/10.1002/anie.201801063

Sallem F (2017) Optimized syntheses and advanced characterizations of titanate nanotubes and their functionalization : towards the development of nanovectors of therapeutic molecules. Theses, Université Bourgogne Franche-Comté

Sallem F, Boudon J, Heintz O, et al (2017a) Synthesis and characterization of chitosan-coated titanate nanotubes: towards a new safe nanocarrier. Dalton Trans. https://doi.org/10.1039/C7DT03029K

Sallem F, Chassagnon R, Megriche A, et al (2017b) Effect of mechanical stirring and temperature on dynamic hydrothermal synthesis of titanate nanotubes. J Alloys Compd 722:785-796. https://doi.org/10.1016/j.jallcom.2017.06.172

Schuemann J, Berbeco R, Chithrani DB, et al (2016) Roadmap to Clinical Use of Gold Nanoparticles for Radiation Sensitization. Int J Radiat Oncol Biol Phys 94:189-205. https://doi.org/10.1016/j.ijrobp.2015.09.032

Singh N, Millot N, Maurizi L, et al (2020) Taurine-Conjugated Mussel-Inspired Iron Oxide Nanoparticles with an Elongated Shape for Effective Delivery of Doxorubicin into the Tumor Cells. ACS Omega 5:16165-16175. https://doi.org/10.1021/acsomega.0c01747

Sruthi S, Loiseau A, Boudon J, et al (2018) In vitro interaction and biocompatibility of titanate nanotubes with microglial cells. Toxicol Appl Pharmacol 353:74-86. https://doi.org/10.1016/j.taap.2018.06.013

Suganya TR, Devasena T (2015) Exploring the Mechanism of Anti-Inflammatory Activity of PhytoStabilized Silver Nanorods. Dig J Nanomater Biostructures 10:277-282

Sun N, Li X, Wang Z, et al (2016) A Multiscale TiO2 Nanorod Array for Ultrasensitive Capture of Circulating Tumor Cells. Acs Appl Mater Interfaces 8:12638-12643. https://doi.org/10.1021/acsami.6b02178

Sun X, Li Y (2003) Synthesis and Characterization of Ion-Exchangeable Titanate Nanotubes. Chem - Eur J 9:2229-2238. https://doi.org/10.1002/chem.200204394

Takakura K (1996) Double-strand breaks in DNA induced by the K-shell ionization of calcium atoms. Acta Oncol 35:883-888. https://doi.org/10.3109/02841869609104041

Thapa B, Diaz-Diestra D, Santiago-Medina C, et al (2018) T1- and T2-weighted Magnetic Resonance Dual Contrast by Single Core Truncated Cubic Iron Oxide Nanoparticles with Abrupt Cellular Internalization and Immune Evasion. ACS Appl Bio Mater 1:79-89. https://doi.org/10.1021/acsabm.8b00016 
Thomas G, Demoisson F, Boudon J, Millot N (2016) Efficient functionalization of magnetite nanoparticles with phosphonate using a one-step continuous hydrothermal process. Dalton Trans 45:10821-10829. https://doi.org/10.1039/C6DT01050D

Thomas G, Demoisson F, Heintz O, et al (2015) Functionalized Fe3O4 nanoparticles: influence of ligand addition sequence and $\mathrm{pH}$ during their continuous hydrothermal synthesis. RSC Adv 5:7861478624. https://doi.org/10.1039/C5RA17452J

Togashi T, Takami S, Kawakami K, et al (2012) Continuous hydrothermal synthesis of 3,4dihydroxyhydrocinnamic acid-modified magnetite nanoparticles with stealth-functionality against immunological response. J Mater Chem 22:9041-9045. https://doi.org/10.1039/c2jm30325f

Wang X, Shao M, Zhang S, Liu X (2013) Biomedical applications of gold nanorod-based multifunctional nano-carriers. J Nanoparticle Res 15:1892. https://doi.org/10.1007/s11051-013-1892-y

White LD, Tripp CP (2000) Reaction of (3-aminopropyl)dimethylethoxysilane with amine catalysts on silica surfaces. J Colloid Interface Sci 232:400-407. https://doi.org/10.1006/jcis.2000.7224

Wu B, Zhang L-J, Zhang C-J, et al (2020) Effect of Poly(ethylene glycol) (PEG) Surface Density on the Fate and Antitumor Efficacy of Redox-Sensitive Hybrid Nanoparticles. ACS Biomater Sci Eng 6:3975-3983. https://doi.org/10.1021/acsbiomaterials.0c00516

Xiao J, Song J, Hodara V, et al (2013) Protective Effects of Resveratrol on TNF-alpha-Induced Endothelial Cytotoxicity in Baboon Femoral Arterial Endothelial Cells. J Diabetes Res UNSP 185172. https://doi.org/10.1155/2013/185172 